\title{
Briefe von Thomas Jordanus von Klausenburg an Carolus Clusius
}

\author{
Robert OfFner, Peter PAuly
}

\begin{abstract}
Despite the rich literature on Thomas Jordanus von Klausenburg (1540-1586), the most important physician and scientist of Transylvanian origin of the sixteenth century, his correspondence has hardly been studied. This article presents five letters from Jordanus to the Flemish physician Carolus Clusius (1526-1609), a famous botanist at the imperial court and the first chief doctor of the margravate of Moravia. The letters of 1574, 1575 and 1585 to Clusius provide a new insight into Jordanus' scholarly network, including numerous contemporary scholars, his private life only a few months before his death, and his interest in botany, including experiments with sassafras oil. ${ }^{*}$
\end{abstract}

\section{Einführung}

Die Kenntnis über den schriftlichen Austausch zwischen humanistischen Gelehrten der res publica litteraria bietet die Chance, einen tiefen Einblick sowohl in ihre Forschungspraxis als auch in die Kommunikation untereinander zu gewinnen. Das gilt auch für Naturforscher, die nicht selten Ärzte waren. Zu den wichtigsten Kommunikationsformen in der Gelehrtenrepublik zählten die Korrespondenz, Bücher, später Zeitschriften und Zeitungen sowie Reisen. Die einzelnen Regionen Europas waren in sehr unterschiedlichem Ausmaß an dem Korrespondenznetzwerk des alten Kontinents beteiligt. Die lateinsprachigen Hochschulstudien an Europas Universitäten und die Studienreisen, auch peregrinatio academica genannt, boten beste Gelegenheit zum Kennenlernen von namhaften Gelehrten und gleichgesinnten Kommilitonen, aber auch zur

\footnotetext{
* Für die sorgfältige Überprüfung der Transkripte und der Übersetzungen sowie für ihre hilfreichen Anregungen und gründlichen Korrekturen danken wir der Redaktion von Humanistica Lovaniensia und Dr. Jeanine De Landtsheer herzlichst. Unser Dank gebührt auch Dr. Mark Emanuel Amtstätter, Staats- und Universitätsbibliothek Hamburg Carl von Ossietzky; Dr. Matthias Nuding, Germanisches Nationalmuseum, Historisches Archiv und Münzkabinett; Dr. Robert Luft, Collegium Carolinum, München; dem Huygens Instituut zu Amsterdam und der Universitätsbibliothek Leiden. Die Überlassung der Reproduktion (Kristina Klein, Wien) der Thomas Jordanus-Medaille aus 1570 verdanken wir Prof. Dr. Hubert Emmerig, Universität Wien. Bei der Korrektur des Typoskriptes und der Übersetzung des zweiten Briefes bot Dr. András László MagyarSemmelweis Orvostörténeti Könyvtár és Levéltár Budapest, wertvolle Hilfe.
} 
"Vernetzung" untereinander. ${ }^{1}$ Auch Siebenbürger waren an dem komplexen Netzwerk der Humanisten in und außerhalb ihrer Heimat beteiligt, allerdings ist uns kein weiterer Arzt im Fürstentum Siebenbürgen des 16. Jahrhunderts bekannt dessen Briefwechsel europäische Dimensionen erreichte, wie das bei Thomas Jordanus von Klausenburg der Fall ist. ${ }^{2}$

Obwohl der spätere mährische Landeschefarzt eine gehobene Position in der europäischen Gelehrtenrepublik seiner Zeit erlangte, stand seine Korrespondenz, im Gegensatz zu seiner Biografie und seinem literarischen Werk, noch nicht im Mittelpunkt wissenschaftshistorischer Untersuchungen. Bislang wurde nur ein Brief von ihm aus Bologna (17. März 1564) an seinen in Padua studierenden Landsmann und ExKommilitonen in Wittenberg, Andreas Marcus Daum aus Bistritz, ${ }^{3}$ ein Brief von Sir Philip Sidney aus Prag (2. März 1575) an Thomas Jordanus und einer von ihm an Carolus Clusius (5. April 1575) veröffentlicht. ${ }^{4}$ Die vom Verfasser des vorliegenden Beitrages bislang identifizierten über 80 Briefe von und an Jordanus, stellen gewiss nur einen Bruchteil seiner Korrespondenz dar. Nichts ist beispielsweise über seine Briefe an seine Familienangehörigen bekannt, deren Existenz jedoch anzunehmen ist, zumal seine Studienreise im Ausland zehn Jahre lang dauerte (1555-1566). Hinsichtlich der Anzahl der bislang identifizierten Briefe an ihn steht der kaiserliche Leibarzt Johannes Crato von Krafftheim (33) an der Spitze, gefolgt von Andreas Dudith (25), Joachim II. Camerarius (6) und Carolus Clusius (5). Obwohl die vorgestellten Briefe als Digitalisate online auffindbar sind, gab es bisher von diesen keine Transkripte, Übersetzungen oder Regesten.

${ }^{1}$ V. Fraknói, A hazai és külföldi iskolázás a XVI. században [Schulbesuch im In- und Ausland im 16. Jahrhundert] (Budapest, 1873); M. Szabó, S. Tonk, Erdélyiek egyetemjárása a korai újkorban: 1521-1700 [Universitätsbesuch der Siebenbürger in der Frühen Neuzeit: 1521-1700] (Szeged, 1992).

2 R. Offner, "Deutsche Universitäten als Ausbildungsstätten siebenbürgischer Mediziner von den Anfängen bis zum Jahr 1850”, in M. Fata, A. Schindling, Gy. Kurucz (ed.), Peregrinatio Hungarica. Studenten aus Ungarn an deutschen und österreichischen Hochschulen vom 16. bis zum 20. Jahrhundert (Stuttgart, 2006), 287-344.

3 "Jordany an Andreas Marci (Daum)", in Elftes Programm des evangelischen Gymnasiums zu Bistritz in Siebenbürgen (Bistritz, 1862), 38-40.

${ }^{4}$ I. Gál, "Sir Philip Sidney levele Kolozsvári Jordán Tamáshoz" ["Brief von Sir Philip Sidney an Thomas Jordanus von Klausenburg”], Korunk 8 (1971), 1240-1242. Der Brief an Clusius wurde publiziert von A. Szabó, "Morva-magyar kapcsolatok a XVI. század második felében" ["Mährisch-ungarische Beziehungen in der zweiten Hälfte des 16. Jahrhunderts"], in J. Jankovics (ed.), Klaniczay-Emlékkönyv. Tanulmányok Klaniczay Tibor emlékezetére [Klaniczay-Gedenkbuch. Studien zum Gedenken an Tibor Klaniczay], (Budapest, 1994), 168-176. 


\section{Thomas Jordanus von Klausenburg (1540-1586)}

Die ältesten Biografien von Thomas Jordanus (ungarisch Jordán Tamás, tschechisch Tomáś Jordán) $)^{5}$ stammen aus dem 18. Jahrhundert, wie in der "Gelehrten-Bibliothek" Specimen Hungariae literatae von David Czvittinger, im Lexikon der Gelehrten und Künstler der Markgrafschaft Mähren von Franz Martin Pelzl sowie in den Ärztebiografien von István Weszprémi. ${ }^{6}$ Grundlegende und mit eigenen Forschungsergebnissen bereicherte Jordanus-Biografien legten, außer Tibor Györy, die beiden Brünner Ärzte und Medizinhistoriker Alexander Rittmann und Gustav Gellner vor. ${ }^{7}$ Zahlreiche Artikel, Kurzbiografien und Lexikoneinträge sind auch in der deutsch-, ungarisch- und tschechischsprachigen medizinhistorischen Literatur zu finden. ${ }^{8} \mathrm{Zu}$ den jüngsten Veröffentlichungen über das balneologische Werk von Jordanus zählen die von Radim Himmler und David Tomíček. ${ }^{9}$

\footnotetext{
${ }^{5}$ Es liegen keinerlei Dokumente vor aufgrund derer anzunehmen wäre, dass Jordanus selber seinen Namen jemals in ungarischer oder tschechischer Schreibweise benutzt hätte. In allen bislang bekannten Quellen erscheint sein Name stets als Thomas Jordan bzw. Jordanus, weshalb wir hier ausschließlich nur diese Varianten verwenden.

${ }^{6}$ D. Czvittinger, Specimen Hungariae literatae, virorum eruditione clarorum natione Hungarorum, Dalmatarum, Croatarum, Slavorum atque Transylvanorum vitas, scripta, elogia et censuras ordine alphabetico exhibens (Francofurti - Lipsiae, 1711), 186-188; F.M. Pelzl, A. Voigt et al., Abbildungen böhmischer und mährischer Gelehrten und Künstler, nebst kurzen Nachrichten von ihren Leben und Werken, vol. 3 (Prag, 1777), 20-24; I. Weszprémi, Magyarország és Erdély orvosainak rövid életrajza / Succincta medicorum Hungariae et Transilvaniae biographia, vol. 1 (Budapest, 1960), 148-153.

${ }^{7}$ T. von Györy, Morbus Hungaricus. Eine medico-historische Quellenstudie, zugleich ein Beitrag zur Geschichte der Türkenherrschaft in Ungarn (Jena, 1901); A. Rittmann, Culturgeschichtliche Abhandlungen über die Reformation der Heilkunst: Thomas Jordanus von Klausenburg (Brünn, 1869), 17-74; G. Gellner, "Tomás Jordán. K 350. vyroci jeho smrti" [“Tomás Jordán. Zu seinem 350. Todestag”], Casopis Matice moravské 60 (1936), 85-140, 315-354.

8 A. Hirsch, W. Haberling et al. (ed.), Biographisches Lexikon der hervorragenden Ärzte aller Zeiten und Völker [vor 1880], 3. Auflage (München - Berlin, 1962), 453-454; J. von Magyary-Kossa, Ungarische medizinische Erinnerungen (Budapest, 1935), 269275; B. Molnár, "Kolozsvári Jordán Tamás, a 400 éves balneológus" ["Thomas Jordan von Klausenburg, der 400jährige Balneologe"], Gyógyászat 24-28 (1939), 373-422; L.A. Magyar, B. Szentmártoni Szabó, "Jordán Tamás (1539-1585)", in P. Köszeghy (ed.), Magyar Müvelödéstörténeti Lexikon: Középkor és kora újkor ["Ungarisches Kulturhistorisches Lexikon: Mittelalter und Frühe Neuzeit"], vol. 4 (Budapest, 2005), 489-490; L.A. Magyar, "Jordán Tamás (1539-1585) 2", in K. Kapronczay, E.Sz. Vizi (ed.), Híres magyar orvosok [Berühmte ungarische Ärzte], vol. 4 (Budapest, 2003), 25-28.

${ }^{9}$ R. Himmler, "Poznatky o lázních v 16. století v díle Tomáse Jordána z Klauznburka" ["Kenntnis der Bäder im 16. Jahrhundert bei Tomás Jordán”], Zprávy Vlastivědného muzea v Oloumuci 284 (2002), 48-56; D. Tomíček, "Water, Environment, and Dietetic
} 
Thomas Jordanus wurde in Klausenburg (Kolozsvár, Cluj-Napoca), Fürstentum Siebenbürgen, nach neuesten Erkenntnissen am 7. Juli 1540 als Sohn von Hans und Magdalena Jordan geboren. ${ }^{10}$

Seine Geburtsstadt war in der Mitte des 16. Jahrhunderts mit ca. 8000 Einwohnern neben Kronstadt und Hermannstadt die drittgrößte, vorbildlich befestigte Stadt und galt als eine der wirtschaftlich und kulturell blühendsten Städte des 1526 in drei Teile zerfallenen Königreichs Ungarn. ${ }^{11}$ Anders als die erstgenannten Städte mit fast ausschließlich deutschsprachiger Bevölkerung, setzte sich die Einwohnerschaft dieser königlichen Freistadt aus einem siebenbürgischsächsischen und einem ungarischen Anteil zusammen, die als "ständische Nationen" gemäß althergebrachter Vereinbarungen (z.B. 1458) eine paritätisch sächsisch-ungarisch besetzte gemeinsame Stadtverwaltung betrieben. Beide Nationen stellten jeweils 50 "Hundertmänner" mit dem zwölfköpfigen Stadtrat an der Spitze und reglementierten gemeinsam sowohl die Nutzung geistlicher und sozialer Einrichtungen als auch die jährlich wechselnde Besetzung kirchlicher und weltlicher Ämter (Stadtpfarrer, Stadtrichter, Königsrichter etc.). ${ }^{12}$ Diese streng geregelte und ausgewogene, jedoch nicht immer konfliktfreie deutsch-

Rules in Bohemian Sources of the Early Modern Times", in A. Classen, M. Sandidge (ed.), Bodily and Spiritual Hygiene in Medieval and Early Modern Literature. Explorations of Textual Presentations of Filth and Water (Berlin - Boston, 2017), 441-457.

10 J. Trausch, F. Schuller (ed.), Schriftsteller-Lexicon der Siebenbürger Deutschen: Schriften zur Landeskunde Siebenbürgens. Ergänzungsreihe zum Siebenbürgischen Archiv, vol. 7.1 (Köln, 1983), 237-240; Weszprémi 1960 (wie Anm. 6), 148-149. Über seinen Vater wurde von seinen Biografen angenommen, dass er Siebenbürger Sachse gewesen sei. Diese Annahme wurde neulich widerlegt: Hans Jordan war ein deutscher Zuwanderer aus dem oberdeutschen Sprachraum. Siehe R. Offner, "Neue Daten zur Biographie von Thomas Jordanus von Klausenburg (1540-1586), Epidemiologe, Balneologe und Protomedicus von Mähren", Sudhoffs Archiv. Zeitschrift für Wissenschaftsgeschichte 103.1 (2018), 89-112.

${ }^{11}$ Die Stadt Klausenburg mit dem Beinamen "Schatzkammer" (auf Ungarisch "kincses Kolozsvár") trat am Ende des 16. Jahrhunderts immer mehr als Zentrum des autonomen Fürstentums Siebenbürgen auf, sie war Standort zahlreicher Staatsakte (Landtage, Synoden, Fürstenwahlen und -hochzeiten etc.): U. Burger, Klausenburg (Cluj-Napoca, 2007); R. Gräf, U. Michailowitsch et al., Klausenburg - Begegnungsorte (Cluj-Napoca, 2009); iid., Klausenburg - Persönlichkeiten (Cluj-Napoca, 2010).

12 P. Binder, Közös múltunk. Románok, magyarok, németek és délszlávok feudalizmus kori falusi és városi együttéléséröl [Unsere gemeinsame Vergangenheit. Über das Zusammenleben von Rumänen, Ungarn, Deutsche und Südslawen im Zeitalter des Feudalismus] (Bukarest, 1982), 201-215. 
ungarische Parität war mit jener der damaligen Städte Ofen (Buda) und Kaschau (Kassa, Košice) vergleichbar. ${ }^{13}$

Der Vater von Thomas, Hans Jordan, stammte laut neuesten Erkenntnissen aus dem oberdeutschen Sprachraum woher er mit seiner ersten Gattin Anna Selge erst 1520 nach Klausenburg zuwanderte und stieg, als wohlhabender Pächter von Silbergruben in den WestKarpaten, in das Patriziat auf. ${ }^{14}$ Er wurde Mitglied des äußeren (1535) und des inneren Stadtrates (1554) und stand dem siebenbürgischsächsischen Reformator, Humanisten und Buchdrucker Kaspar Helth (Heltai Gáspár) nahe, der mutmaßlich einen förderlichen Einfluss auf Thomas Jordans geistige Entwicklung hatte. ${ }^{15}$

Nach dem Besuch des zu jener Zeit lutherisch geprägten Kollegiums (Gymnasium) seiner Geburtsstadt ${ }^{16}$ trat er 1555 seine Studienreise an und immatrikulierte sich in Wittenberg, ${ }^{17}$ wo er, wie wenige Jahre zuvor auch sein Halbbruder Johannes Jordan, artes liberales studierte und zum Schüler von Melanchthon wurde. ${ }^{18}$ Über seinen Studienaufenthalt im Zentrum der lutherischen Reformation ist wenig bekannt, außer, dass er Freundschaft mit Hubert Languetus schloss. 1560 folgte

${ }^{13}$ Für weiterführende Literatur: R. Schuller, Aus der Vergangenheit Klausenburgs (Cluj-Klausenburg, 1924), 69-74; G. Lang, Die Nationalitätenkämpfe in Klausenburg im ausgehenden Mittelalter (München, 1941).

${ }^{14}$ Offner 2018 (wie Anm. 10), 15.

15 Darauf lässt die Widmung seiner Edition des Trostbüchleins von Johann Spangenberg aus dem Jahr 1551 schließen [USTC 305101]. Trausch, Schuller 1983 (wie Anm. 10), 237-240; E. Szegedi, "Die Reformation in Klausenburg", in V. Leppin, U.A. Wien (ed.), Konfessionsbildung und Konfessionskultur in Siebenbürgen in der frühen Neuzeit (Stuttgart, 2005), 77-88.

${ }^{16}$ Jordanus gedenkt in seinem Werk Luis novae in Moravia exortae descriptio (Francoforti, 1580) [USTC 698300] seinem Lehrer, dem "ersten Förderer meiner Seele", Vizaknai Molnár Gergely (†1558), einem lutherischen Gymnasiallehrer und Mitstreiter des Klausenburger Reformators Kaspar Helth. Vizaknai ließ eine lateinische Grammatik in Druck erscheinen.

17 Thomas Jordan Clausenburgensis Transylvanus immatrikulierte sich am 23. November 1555. Siehe Szabó, Tonk 1992 (wie Anm. 1), 274.

18 Johannes Jordan Transylvanus immatrikulierte sich in Wittenberg am 9. Juni 1550. Siehe Szabó, Tonk 1992 (wie Anm. 1), 100. Jordanus erwähnt später Wittenberg nicht in einem Widmungsschreiben an den kaiserlichen Leibarzt Giulio Alessandrino unter seinen Bildungsstätten. Für seine intellektuelle Prägung (z.B. durch Melanchthon) und die Entwicklung seines späteren gelehrten Netzwerkes war Wittenberg dennoch relevant. $\mathrm{Zu}$ seinen dortigen Kommilitonen zählten bekannte Persönlichkeiten wie der Franzose Hubert Languetus, die Ungarländer und Siebenbürger Christian Schaeseus, Calixtus Honterus, Georg Purkircher, Christoph Ungnad, János Vitus Balsaráti, Balázs Szikszai Fabricius, Paul Kertzius, Andreas Marcus Daum und viele andere. Siehe Fraknói 1873 (wie Anm. 1), 303. 
eine Reise (vermutlich auf Anraten von Languetus) nach Paris, wo er neben Philosophie auch Medizin hörte. ${ }^{19}$ Er selber gab später Luis Duret (1527-1586) und Jacques Goupyl (1525-1564), beide Schüler des berühmten Medizinprofessors Jean Fernel (1497-1558), als seine Lehrer der Arzneikunst an der Seine an. Am 1. Oktober 1561 immatrikulierte er sich an der berühmten medizinischen Fakultät zu Montpellier, wo er zu den Hörern der namhaften Naturforscher Guillaume Rondelet (1507-1566) und Laurent Joubert (1529-1583) zählte. ${ }^{20}$ Vermutlich war der Ausbruch des ersten französischen Religionskrieges ("Hugenottenkriege") der Grund für die Kürze seines Aufenthaltes, denn 1562 wechselte Jordanus an die Universität Valence in der Dauphiné, wo er bald - zeitgleich mit Leonhard Rauwolf aus Augsburg, dem später bedeutenden Arzt und Botaniker - zum Dr. med. promovierte. ${ }^{21}$ Im selben Jahr immatrikulierte er sich in Basel, wo damals u.a. Oswald Baer und Felix Platter wirkten. Jordanus setzte bald seine Bildungsreise nach Italien fort und besuchte - am 1. Okto-

19 Siehe den Brief von Thomas Jordan aus Klausenburg an Hubert Languetus in Wittenberg (14. April 1559), www.aerztebriefe.de/id/00030854. Hubert Languetus (15181581) ging an die Universität Poitiers, um Jura zu studieren, doch er war auch an Theologie, Geschichte, Natur- und Politikwissenschaften interessiert. Danach besuchte er Padua und Bologna und bereiste Italien und Spanien. 1549 ging Languetus nach Wittenberg, wo er von Melanchthon gastlich aufgenommen wurde, den er auf seinen Reisen begleitete. Als er während der Protestantenverfolgungen aus Frankreich ausgewiesen wurde, kehrte er nach Wittenberg zurück und trat 1559 auf Melanchthons Empfehlung als Diplomat in den Dienst des Kurfürsten von Sachsen, in welcher Stellung er bis 1577 verblieb. Der Kurfürst entsandte ihn an verschiedene Herrscherhöfe. So war Languetus 1575 am Wiener Hof Kaiser Maximilians II. Dort war seine Stellung als Calvinist prekär, was ja recht klar durch Jordanus bzw. seinen Informanten Crato zum Ausdruck kommt. Siehe B. Nicollier de Weck, "Es gibt keinen tugendhaften Herrscher mehr auf der Welt. Hubert Languet, ein Franzose im Dienst Kurfürst Augusts von Sachsen", in D. Syndram (ed.), Luther und die Fürsten: Selbstdarstellung und Selbstverständnis des Herrschers im Zeitalter der Reformation (Dresden, 2015), 201-208.

${ }^{20}$ Joubert war Autor des Buches De balneis antiquorum und beherbergte seinen siebenbürgischen Studenten Jordan. Siehe J. Trausch, F. Schuller, H.A. Hienz (ed.), Schriftsteller-Lexikon der Siebenbürger Deutschen. Bio-bibliographisches Handbuch für Wissenschaft, Dichtung und Publizistik, vol. 7.7 (Köln, 2000), 383.

${ }^{21}$ A. Huttmann, "Jordanus Thomas Arzt", in Ostdeutsche Gedenktage 1985. Persönlichkeiten und historische Ereignisse (Bonn, 1984), 35-37; F.W. Rieppel, "Leonhard Rauwolf. Ein Beitrag zu seiner Biografie", Deutsche medizinische Wochenschrift 80 (1955), 653-655; S. Herde, T. Walter, "Neues zur Biographie des Augsburger Arztes und Orientreisenden Leonhard Rauwolf (1535?-1596)", Sudhoffs Archiv. Zeitschrift für Wissenschaftsgeschichte 94 (2010), 129-156. 
ber 1562 - den Stadtarzt, Universalgelehrten und Naturforscher Conrad Gessner in Zürich, zu dessen Anhänger er wurde. ${ }^{22}$

Am 23. Oktober 1562 immatrikulierte er sich bereits an der Universität Padua, wechselte jedoch 1564 nach Bologna, wo er Hörer von Ulysse Aldrovandi war und setzte seine peregrinatio academica in Pisa und ein Jahr später in Rom fort. Aus Italien zurückgekehrt, ließ Jordanus Anfang des Jahres 1566 an der Universität Wien seinen Doktortitel von Valence durch repetitio nostrifizieren und sich in die Medizinische Fakultät aufnehmen.

Nur wenige Monate später wurde Jordanus auf Empfehlung des Dekans der Medizinischen Fakultät, Benjamin Löbschütz, vom Kaiser Maximilian II. zum Generalarzt des kaiserlichen Heeres ernannt. Im Feldlager von Marschall Ludwig Ungnad in Komorn (Komárom, Komárno) war nämlich eine schwere Seuche ausgebrochen, die als lues Pannonica oder morbus Hungaricus bezeichnet wurde. ${ }^{23}$ Vom Feldlager zurückgekehrt praktizierte er in Wien und wirkte an der Medizinischen Fakultät. Der Einladung des Wissenschaftsmäzens Karl Freiherr von Zierotin (Žerotín) und den "Böhmischen Brüdern" folgend, übersiedelte er im Sommer 1569 nach Brünn (Brno).

Nach dem Besuch seines Kollegen und Gönners Johannes Crato von Krafftheim am Prager Kaiserhof Maximilians II. und einem anschließenden Kuraufenthalt in Karlsbad wurde Thomas Jordanus 1570 von den mährischen Ständen zum Primus medicus publicus Moraviae oder Protomedicus der Markgrafschaft Mähren gewählt. Er gab 1575 in Basel die von ihm erweiterte Historia Boiemica von Jan Dubravius heraus. ${ }^{24}$ Noch im selben Jahr erhob man ihn in den mährischen Ritterstand mit dem Prädikat "von Klausenburg" (z Klauznburgku oder de Clausoburgo), nach seiner Geburtsstadt. 1577 brach in Brünn eine zahlreiche Opfer fordernde Seuche aus, die Jordanus als extragenital übertragene Syphilis identifizierte. ${ }^{25}$ Seine Thesen publizierte er 1580 unter dem Titel Brunno-Gallicus, seu luis novae in Moravia exortae

${ }^{22}$ R. Offner, "Neues zu Conrad Gessners Kontakte zu Ungarn und Siebenbürgern. Ein Brief des Klausenburger Arztes Thomas Jordanus aus Padua (1563)", in U.B Len, P. Optiz (ed.), Conrad Gessner und die Renaissance der Wissenschaften / Conrad Gessner and the Renaissance of Learning (Berlin - New York, im Erscheinen).

${ }^{23}$ Diese Beobachtung veröffentlichte Jordanus erstmalig 1576 unter dem Titel Pestis phaenomena seu de iis quae circa febrem pestilentem apparent exercitatio in Frankfurt [USTC 698444].

${ }^{24}$ USTC 667031.

${ }^{25}$ H. Haeser, Grundriss der Geschichte der Medicin, vol. 3 (Jena, 1884), 278, 376. 
descriptio bei Andreas Wechel in Frankfurt am Main. ${ }^{26}$ Jordanus hat darüber hinaus weitere hoch beachtete Bücher verfasst, die u.a. die Heilwässer Mährens behandelten. ${ }^{27}$

In den letzten Lebensmonaten litt Thomas Jordanus an einer Lähmung und starb am 12. Februar 1586, vermutlich infolge einer weiteren Apoplexie, im Alter von 46 Jahren. ${ }^{28}$ Er hinterließ fünf Kinder, die von dem zweiten Ehemann seiner Witwe, dem Stadtarzt Achilles Cromerus, aufgezogen wurden. ${ }^{29}$ Die Nachkommen von Thomas Jordanus von Klausenburg waren drei Jahrhunderte lang in Böhmen in gehobenen gesellschaftlichen Kreisen nachweisbar, bis das Geschlecht im 19. Jahrhundert erlosch. ${ }^{30}$

${ }^{26}$ USTC 698300. Vgl. Huttmann 1985 (wie Anm. 21), 36: "Nach dem 13. Dezember 1577 brach in Brünn eine neue Seuche aus, befiel etwa 180 Personen aus der Stadt und den Vororten, sowie viele Ortsfremde; sie ging von einer Bad-Stube aus, wo die Besucher über skarifizierten Hautstellen geschröpft worden waren, wonach an diesen Stellen große Geschwüre entstanden. Jordanus stellte fest, daß es sich um eine extragenital übertragene Syphilis handelte, und die Epidemie erlosch, als die Badestube zu Ostern 1578 auf seinen Vorschlag geschlossen wurde." Siehe auch Györy 1901 (wie Anm. 7).

${ }^{27}$ Sein Werksverzeichnis siehe bei Trausch, Schuller, Hienz 2000 (wie Anm. 20), 383; Trausch, Schuller 1983 (wie Anm. 10), 237-240.

28 Siehe den Brief von Johannes Crato an Joachim Camerarius II. (Breslau, 13. März 1585), www.aerztebriefe.de/id/00009090.

29 Achilles Cromer(us) aus Neisse in Schlesien besuchte dort das Gymnasium (1565) und wirkte als Lehrer und später als bischöflicher Rat in Breslau. Bereits damals botanisierte er und sendete Pflanzen an Carolus Clusius: F. Wimmer, Flora von Schlesien preussischen und österreichischen Antheils (Breslau, 1844), 139. Cromer studierte u.a. in Padua (1583 bis 1585) und besuchte Bologna (1583). Seinen medizinischen Doktorgrad erhielt er in Padua am 25. Februar 1585 beim Pfalzgrafen Ferrando de Amadis. Danach wirkte er in Brünn als Arzt der Markgrafschaft Mähren: C. Zonta, Schlesische Studenten an italienischen Universitäten. Eine prosopographische Studie zur frühneuzeitlichen Bildungsgeschichte (Stuttgart, 1999), 177-178; J. Graetzer, Lebensbilder hervorragender schlesischer Ärzte aus den letzten vier Jahrhunderten (Breslau, 1899), 33. Cromer ist nicht auffindbar bei M. Sachs, Historisches Ärztelexikon für Schlesien, vol. 1 (Wunstorf, 1997), 240. Im Projekt Frühneuzeitliche Ärztebriefe des deutschsprachigen Raums (1500$1700)$ ist der aus Schlesien stammende Arzt vertreten. Siehe www.aerztebriefe.de. Bekannt ist, dass Cromer in den Jahren nach 1585 intensiven Briefwechsel mit Clusius führte: www.haraldfischerverlag.de/hfv/sammlungen/trew.php.

${ }^{30} \mathrm{~J}$. Bergmann, Medaillen auf berühmte und ausgezeichnete Männer des oesterreichischen Kaiserstaates, vom XVI. bis zum XIX. Jahrhunderte. In treuen Abbildungen, mit biographisch-historischen Notizen (Wien, 1857), 109-114; Rittmann 1869 (wie Anm. 7), 17-74; P. Binder, "Medicii clujeni din secolul al XVI-lea" ("Die Klausenburger Ärzte des 16. Jahrhunderts”], Anuarul Institutului de Istorie Cluj-Napoca 30 (1991), 203-206. 


\section{Carolus Clusius (1526-1609)}

Der Aristokratensohn Carolus Clusius (Charles de l'Escluse/Écluse) wurde im flämischen Atrecht (heute Arras in Frankreich) geboren. Nach in Gent verbrachter Jugend studierte er ab 1546 alte Sprachen (Collegium Trilingue) und Jurisprudenz in Löwen. 1548 wechselte er nach Marburg, wo ihn sein Landsmann Andreas Hyperius (1511-1564) für die Idee der Reformation gewann. 1549 ging er nach Wittenberg, gab auf Anraten Melanchthons das Rechtsstudium auf, und widmete sich dem Studium der Medizin. ${ }^{31}$

Nach kurzem Aufenthalt in Straßburg und in der Schweiz (1550) studierte er Arzneikunde an der berühmten Medizinschule zu Montpellier beim Gelehrten Guillaume Rondelet und half seinem Lehrer beim Redigieren seines Fischbuches. Im Anschluß an die prägenden Jahre in Montpellier kehrte er 1554 in die südlichen Niederlande zurück und ließ sich in Antwerpen nieder. Hier schuf er 1557 auch sein erstes botanisches Werk, eine Übersetzung des gerade erschienenen Cruydt-boeck von Rembert Dodonaeus ins Französische. ${ }^{32} 1560$ war er in Paris an der Bewegung der Hugenotten beteiligt, flüchtete dann 1562 mit dem jungen Breslauer Thomas Rehdiger (1540-1576), dessen Mentor er bis 1563 war, nach Löwen. Es folgten Jahre wechselnder Beschäftigung, die mit Reisen, Forschungsaufenthalten und botanischen Exkursionen in der Schweiz, im Piemont und auf die Iberische Halbinsel verbunden waren, wo er mehr als 200 neue Pflanzenarten entdeckt, gesammelt und beschrieben hat. Nach einer Exkursion mit dem Augsburger Bankierssohn Jakob Fugger nach Spanien und Portugal kehrte er in die Niederlanden (Brügge und Mecheln) zurück. Auf einer Reise durch England entdeckte er das spanische Buch über die Flora der "Neuen Welt" von Nicolas Monardes und veröffentlichte es bald in lateinischer Übersetzung (1574). ${ }^{33}$

${ }^{31}$ E. Schultheisz, "Carolus Clusius Atrebatis", Orvosi Hetilap 107.5 (1966), 226-228; Id., "Carolus Clusius Atrebatis", in Id., Az orvoslás kultúrtörténetéböl [Aus der Kulturgeschichte der Heilkunde] (Piliscsaba, 1997), 19-20. Kurzbiographie von Clusius: A. Louis, "Clusius, (de l'Ecluse) Carolus, botanicus", in Nationaal Biografisch Woordenboek, vol. 1 (Brussel, 1964), 312-219.

32 USTC 24365.

${ }^{33}$ USTC 401630. Siehe H. Dolezal, "Clusius, Carolus", in Neue Deutsche Biographie, vol. 3 (Berlin, 1957), 296-298; Schultheisz 1997 (wie Anm. 31), 20; F. Egmond, "Clusius and Friends. Cultures of Exchange in the Circles of European Naturalists", in Ead., P. Hoftijzer et al. (ed.), Carolus Clusius. Towards a Cultural History of a Renaissance 
Von entscheidender Bedeutung für seine weitere wissenschaftliche Laufbahn war der Ruf nach Wien im Jahr 1573. Kaiser Maximilian II. hatte Clusius beauftragt, dort einen Medizinalkräutergarten (hortus medicus) einzurichten und zu leiten. Später sollte er auch den kaiserlichen Garten in Prag anlegen. Der Mediziner und Naturforscher Clusius gehörte, ohne kaiserlicher Leibarzt zu sein, dem späthumanistischen Gelehrtenkreis der Kaiserstadt an. Hier schrieb er seine spanische Flora: Rariorum aliquot stirpium per Hispanias observatarum historia. ${ }^{34}$ Durch botanische Exkursionen auf Ötscher und Schneeberg hat Clusius wesentlich zur Kenntnis der Alpenflora beigetragen. Als 1576 Rudolf II., der Sohn Maximilians II., alle Hofangestellten protestantischen Glaubens entließ, fand er in Graf Balthasar Batthyány, dem Burgherrn von Güssing (Németújvár), einen großzügigen Förderer. Er blieb zwar in Wien, bei seinem Arztkollegen Johann Aicholz wohnhaft, setzte aber seine botanischen Wanderungen fort, die ihn vor allem durch Niederösterreich, das Burgenland und Südwest-Ungarn führten.

Auf Batthyánys Burg Schlaining verfasste und veröffentlichte Clusius 1583 sein bedeutendes Werk Stirpium nomenclator Pannonicus, die erste österreichische Pflanzenkunde. ${ }^{35}$ Seine Arbeiten über die Pflanzen in Österreich und Ungarn blieben längere Zeit maßgebend, zumal diese Werke die Beschreibung aller auffindbaren Pflanzen, einschließlich der Kultur- und exotischen Zierpflanzen, darstellten. 1587 verhandelte Clusius über eine Berufung an die Universität Jena, die jedoch nicht zustande kam. Er siedelte im nächsten Jahr nach Frankfurt am Main über, wo er für sechs Jahre ein Forschungsstipendium (subsidium) des an Botanik und Naturwissenschaften sehr interessierten Landgrafs Wilhelm IV. von Hessen-Kassel genoss. Hier war er für dessen Botanischen Garten zuständig und beschäftigte sich mit Übersetzungsarbeiten. ${ }^{36}$

Naturalist (Amsterdam, 2007), 9-48; Ead., The World of Carolus Clusius. Natural History in the Making 1550-1610 (London, 2010), 654-660.

${ }^{34}$ USTC 401699. Siehe A. Pavord, Wie die Pflanzen zu ihren Namen kamen. Eine Kulturgeschichte der Botanik. Aus dem Englischen von Heiner Kober, 2nd ed. (Berlin, 2008), 344-350; G. Lewis, "Clusius in Montpellier, 1551-1554. A Humanist Education Completed?", in Egmond, Hoftijzer et al. 2007 (wie Anm. 33), 65-98, hier 85.

${ }_{35}$ USTC 402015. Siehe A. Pál, "Clusius, Carolus, Charles de Lécluse, Jules-Charles Lécluse; Arras, 1526. febr. 19. - Leiden, 1609. ápr. 4”, in P. Köszeghy (ed.), Magyar Müvelödéstörténeti Lexikon [Ungarisches kulturhistorisches Lexikon], vol. 2 (Budapest, 2004), 57-59; A. Ubrizsy Savoia, "Some Aspects of Clusius' Hungarian and Italian Relations", in Egmond, Hoftijzer et al. 2007 (wie Anm. 33), 267-292.

${ }_{36}$ Dolezal 1957 (wie Anm. 33), 298. 
1593 folgte Clusius dem Ruf an die Universität Leiden auf den Lehrstuhl für Botanik. Dort baute er den bestehenden hortus academicus um und entwickelte diesen zum führenden Botanischen Garten Europas. Den Großteil seiner Schriften veröffentlichte er während seiner Leidener Jahre. Große Bedeutung für die Mykologie hat sein erstmals 1583 in Antwerpen erschienenes Werk Rariorum aliquot stirpium per Pannoniam, Austriam et vicinas quasdam provincias observatarum historia. ${ }^{37}$ Das Werk, das u.a. eine Auflistung ungarischer Pflanzennamen (Stirpium nomenclator Pannonicus) beinhaltet und früher seinem Exkursionsbegleiter, dem Güssinger Prediger István Beythe, zugeschrieben wurde, war die erste umfassende Pilzmonografie und gleichzeitig die erste regionale Pilzflora, in der 105 in Westungarn vorkommende Pilze beschrieben werden. ${ }^{38}$ Er setzte mit seinem Fungorum in Pannoniis brevis historia (Antwerpen, 1601) neue Maßstäbe für die Systematisierung der Pilze und gilt als einer der Väter der Mykologie.

Clusius förderte auch die Verbreitung vieler Nahrungs- und Zierpflanzen, so verdankt ihm Wien und Österreich unter anderem die Einführung der Rosskastanie (1576), der Tulpe und der Kartoffel (1588) sowie der Kaiserkrone. Clusius kann nicht zuletzt auch durch Verbreitung und Züchtung exotischer Pflanzen als einer der bedeutendsten Wegbereiter der wissenschaftlichen Botanik angesehen werden, auch wenn er heute hauptsächlich wegen der Einführung der Tulpe nach Holland bekannt ist. In Leiden kultivierte er etwa 1200 verschiedene Pflanzenarten, wobei den Kern seiner Sammlung die Heilpflanzen bildeten. ${ }^{39}$ Seine Werke, in denen erstmals nicht mehr die Nützlichkeit der Pflanzen im Mittelpunkt steht, zeichnen sich durch exakte Angaben sowie viele, oft überraschende, Details bei den Artbeschreibungen aus und zeigen schon Ansätze einer binären Nomenklatur mit gelegentlicher Beifügung des Namens des Autors. ${ }^{40}$

37 USTC 401990.

${ }^{38}$ Pavord 2008 (wie Anm. 34), 365-369; S.A. Aumüller (ed.), Ch. L'Ecluse, Fungorum in Pannoniis observatorum brevis historia (Budapest, 1983).

${ }^{39}$ Dolezal 1957 (wie Anm. 33), 298: "Die Arbeiten über die iberische und über die österreichisch-ungarische Pflanzenwelt, für diese Gebiete durch mehr als 100 Jahre maßgebend, sind die ersten größeren Länderfloren überhaupt; sein Werk über die Pilze ist deren erste Monographie. Botanische Exkursionen, so u.a. auf den Ötscher und Schneeberg, stempeln ihn zum ersten Erschließer der Alpenflora, die er auch in seinem Wiener Garten zog und beobachtete."

${ }^{40}$ Egmond 2010 (wie Anm. 33). 


\section{Briefwechsel zwischen Thomas Jordanus und Carolus Clusius}

Die Freundschaft zwischen Thomas Jordanus und Carolus Clusius war bislang in der Sekundärliteratur nicht bekannt und unter den "ungarländischen" Freunden von Clusius wurde Jordanus nicht wahrgenommen. Dóra Bobory sind elf Clusius-Briefe an dessen Mäzen und Botanikerfreund Graf Balthasar Batthyány und fünf von jenem an ihn bekannt, aber keiner an Jordanus. ${ }^{41}$ Der flämische Gelehrte stand in Kontakt mit dem Humanistenkreis um István Radéczy in Pressburg (Bratislava, Pozsony), mit dem reformierten Pfarrer, Schriftsteller und Botaniker István Beythe, dem Arzt und Botaniker Georg Purkircher in Pressburg, sowie dem Mediziner und Hofhistoriker Johannes Sambucus (Zsámboky) in Wien und später auch mit dem Arzt und Botaniker Johannes Hertelius aus Klausenburg. ${ }^{42}$ Mit diesem Kreis stand auch Jordanus in Verbindung. Er soll zu Georg Purkircher, seinem Ex-Kommilitonen von Wittenberg und Padua, der im nahen Pressburg wirkte, engen freundschaftlichen Kontakt gepflegt haben. ${ }^{43}$

Die hier vorzustellenden Briefe von Jordanus dienen nicht nur als Beweis für den geistigen und materiellen Austausch zweier passionierter Naturforscher, sondern auch für die Freundschaftsbeziehung zwischen dem in Wien lebenden Flamen Clusius und dem in Brünn wirkenden Siebenbürger Jordanus. Wo und wann die beiden Männer sich kennengelernt haben, ist nicht übermittelt und aus den Briefen auch nicht erkennbar. Einerseits kommt Paris in Betracht, zumal dass Clusius und Jordanus sich 1560 und 1561 zeitgleich in Paris aufhielten und beide mit dem Arzt und Naturforscher Jacques Goupyl, einem Freund von Rondelet (Montpellier), in engem Kontakt standen. Andererseits dürften Pressburg und Wien Anlass zum Kennenlernen geboten haben, wo Carolus Clusius von 1573 bis 1577 Hofbotaniker Maximilians II. war. Die ersten Briefe stammen gerade eben aus dieser Zeit.

Die erhaltene Clusius-Korrespondenz bietet einen faszinierenden Einblick in die Welt der Gelehrten und die naturkundliche Praxis des 16.

41 D. Bobory, "Qui me vice amabat. Carolus Clusius and Boldizsár Batthyány”, in Egmond, Hoftijzer et al. (wie Anm. 33), 119-144.

42 R. Offner, "Ein bisher unbekannter Brief des siebenbürgischen Arztes Joannes Hertelius an den flämischen Botaniker Carolus Clusius vom 8. Februar 1593”, Orvostörténeti Közlemények / Communicationes de historia artis medicinae 206-209 (2009), 225-242.

43 Purkircher widmete ihm sogar ein Gedicht. Siehe M. Okál (ed.), Georg Purkircher, Opera quae supersunt omnia (Budapest, 1988), 119. 
Jahrhunderts. Sie besteht aus 1600 Briefen, von denen fast 1200 in der Universitätsbibliothek in Leiden aufbewahrt werden. Die Briefe wurden von 330 Korrespondenten zwischen 1549 und 1609 in sechs verschiedenen Sprachen und aus zwölf europäischen Ländern geschrieben. Im Huygens Instituut zu Amsterdam ist das Projekt Clusius Correspondence angesiedelt, das die Sammlung und die digitale Edition der Briefe zum Ziel hat. ${ }^{44}$

Die vorgestellten Briefe sind sowohl der noch unerschlossenen Jordanus-Korrespondenz, von welcher bislang etwas mehr als 80 Briefe von und an Jordanus bekannt geworden sind, als auch dem Clusius-Briefwechsel zuzuordnen. ${ }^{45}$ Alle Briefe sind im Würzburger Projekt Ärztebriefe gelistet, im Gegensatz zum Projekt des Huygens-Instituuts in Amsterdam, wo derzeit nur die letzten beiden aus 1585 aufgeführt sind. Es bietet sich somit an, diese Sammlung mit den Jordanus-ClusiusBriefen von 1574 und 1575 zu ergänzen. Neu ist überhaupt der Nachweis der vermutlich langjährigen freundschaftlichen Beziehung zwischen den beiden Medizinern, zumal auch im Kreise der bislang bekannten "ungarländischen" Freunde von Clusius, wozu vor allem Graf Balthasar Batthyány und dessen Hofgeistlicher István Beythe, der Pressburger Stadtarzt Georg Purkircher sowie der Polyhistor Andreas Dudith gehörten, Thomas Jordanus nicht bekannt war. ${ }^{46}$ Die fünf Schreiben beinhalten neue Erkenntnisse sowohl bezüglich seiner Biografie als auch seines humanistischen Netzwerkes des mährischen Landeschefarztes Thomas Jordanus.

44 Clusius Correspondence. A Digital Edition-in-Progress. A Collaborative Editing Project made possible by the Huygens Institute for the History of the Netherlands and the Clusius Community 2.0: http://clusiuscorrespondence.huygens.knaw.nl. Die beiden Briefe von 1585 befinden sich derzeit in der Datenbank Huygens-Instituuts zusammen mit fotografischen Reproduktionen, aber ohne bearbeitet oder übersetzt zu sein.

${ }^{45}$ Bedauerlicherweise sind derzeit keine weiteren Briefe von Jordanus an Clusius oder umgekehrt übermittelt, obwohl von der Existenz solcher auszugehen ist. Die Edition der Korrespondenz von Thomas Jordanus ist von Robert Offner geplant.

${ }^{46}$ E. Schultheisz, Fejezetek az orvosi müvelödés történetéböl [Kapiteln aus der ärztlichen Kulturgeschichte] (Piliscsaba, 2006), 138-140; Gy. Istvánffi, Études et commentaires sur le code de l'Escluse augmentés de quelques notices biographiques (Budapest, 1900); Id., A Clusius-codex mykologiai méltatása. Adatokkal Clusius életrajzához. 22 szöveg közé nyomott ábrával és 91 színes könyomatú mülappal, a leideni Clusius-Codex másolatával [Die mykologische Würdigung des Clusius-Kodex. Daten zu Clusius' Biographie mit 22 gedruckten Abbildungen und 91 farbigen Seiten mit einer Kopie des ClusiusCodex von Leiden] (Budapest, 1898-1900). 
Im ältesten Brief von Jordanus (vom 27. Juni 1574) bedankt sich der Schreiber, nach der Begrüßung bei "seinem weitaus liebsten Freund" der Manier der Renaissance-Humanisten für ein unbenanntes Buch, das er von Clusius zugesandt, bzw. geschenkt bekam. Er las das Buch, fand es hilfreich und tat gleich seine Absicht kund, sich dafür revanchieren zu wollen und lud seinen Freund nach Brünn ein. Natürlich sollte ein solcher Besuch zum Botanisieren in der unmittelbaren Umgebung der mährischen Stadt genutzt werden, auch wenn, wie er schreibt, die Aussichten auf spektakuläre Funde dort eher gering seien. Und damit bekommt der Gedankenaustausch gleich einen botanischen Schwerpunkt. Aus diesem Brief erfahren wir, dass er zu jenem Zeitpunkt mit zwei weiteren namhaften Ärzten in Briefwechsel stand. Er pflegte Naturalientausch (Pflanzensamen, -zwiebeln), wie es unter Botanikern weit verbreitet war, mit dem berühmten Arzt und Botaniker Pietro Andrea Mattioli (1501-1578), dem vormaligen kaiserlichen Leibarzt und Hofrat, der bereits seit 1568 wieder in Italien lebte und 1578 in Trient einer Pestepidemie zum Opfer fiel. ${ }^{47}$ Der zweite Brieffreund war der Dichter und Humanist Johannes Posthius (1537-1597), der damals als Arzt des Domkapitels und des Fürstbischofs Julius Echter in Würzburg tätig war und sich 1575 und 1577 am kaiserlichen Hof in Wien aufhielt. ${ }^{48}$ Von ihm soll Jordanus ein Jahr zuvor (1573) einen Sonnenblumenkern erhalten haben, aus welchem sich, zu seiner Freude, eine überraschend große Pflanze entwickelte. Im gleichen Atemzug teilt er mit, dass aus den von Clusius zugesandten Sämereien noch

47 Pietro Andrea Mattioli, Arzt und Botaniker, bedeutend durch Übersetzung und Kommentierung der Materia medica des Dioscurides und andere botanische Werke. Nach Studium in Padua wirkte er zeitweilig in Rom, Trient, Görz und ab 1555 am kaiserlichen Hof (Prag, Ambras und Wien) als Leibarzt und Hofrat. Zur Zeit des Kontaktes mit Jordanus lebte Mattioli in Trient. Botanisch ist er bis heute durch die nach ihm als "Matthiola" benannte Familie der Kreuzblütler präsent. Siehe C. Preti, "Mattioli (Matthioli), Pietro Andrea", in Dizionario biografico degli italiani, vol. 72 (Roma, 2008), 308-312.

48 Johannes Posthius, ein von seinen Zeitgenossen sehr geschätzter Arzt, Botaniker und Humanist, der dank der Qualität seiner Gedichte schnelle überregional bekannt wurde. In Germersheim geboren, studierte er in Heidelberg Philosophie und Medizin, reiste nach Italien und promovierte in Medizin in Valence (1567). Er wirkte in Antwerpen bis zu seiner Berufung (1569) als Leibarzt des Fürstbischofs Julius Echter in Würzburg. 1585 wechselte er an den pfälzischen Hof zu Kurfürst Friedrich IV. nach Heidelberg: K. Karrer, Johannes Posthius (1537-1597). Verzeichnis der Briefe und Werke mit Regesten und Posthius-Biographie (Wiesbaden, 1993), 64-66, 656-657; Id, "Posthius, Johannes", in Neue Deutsche Biographie, vol. 20 (Berlin, 2001), 656-658. Posthius stand seit etwa 1567 in Briefkontakt mit Clusius und die beiden kannten sich persönlich (1577). Ein Briefaustausch zwischen Posthius und Jordanus ist bislang nicht belegt. 
nichts “aufgegangen" sei. Gleich im Anschluss daran nimmt er Bezug auf einen "falschen Ankläger" von Clusius, vermutlich aus einem der vorhergehenden Briefe des Adressaten, dessen Identität er gerne erfahren möchte. Seinen relativ kurzen Brief schließt Jordanus mit einer Anekdote botanischen Inhalts ab. Im Postskript grüßt er auch den Vermieter von Clusius, Johann Emmerich Aicholz (Aichholtz). ${ }^{49}$ Diesen Wiener Arzt und Botaniker kannte und schätzte Jordanus noch aus jener Zeit, als auch er selbst Mitglied der Medizinischen Fakultät von Wien gewesen war (1566-1569), Grund genug, ihn jedes Mal durch den Briefempfänger grüßen zu lassen.

Als derzeit zweitältester Brief von Jordanus an Clusius gilt ein bereits im Druck veröffentlichtes Schreiben vom 5. April 1575, das erst unlängst im Würzburger Projekt Ärztebriefe aufgelistet wurde. ${ }^{50}$ Auch in diesem Schreiben geht es um die Pflanzenkunde, insbesondere der Gedankenaustausch über eine nicht näher beschriebene Art Pflaume und die Myrrhe. Erwähnung findet eine Art gefälschte Myrrhe (Weihrauchharz), die Jordanus in Wien angeboten worden sei. In diesem Zusammenhang erwähnt er den berühmten zeitgenössischen Arzt aus Ungarn, János Vitus Balsaráti, von welchem er erfahren haben soll, dass auch in den Höhlen und Grotten um Beregszász (Beregovo) solche ölartige Flüssigkeit tropft und zu einer Art Harz erhärtet. ${ }^{51}$ Danach folgt eine mit

49 Der gebürtige Wiener Johann Emmerich Aicholz (1520-1588) studierte an der Universität Wien, ging 1543 nach Wittenberg, wo er 1547 Magister wurde und Luthertum übertrat. Ab 1550 ging er als Erzieher auf Reisen nach Frankreich und Italien; seit 1555 in Padua, dort erwarb er den Doktorgrad der Medizin und der Philosophie. 1557 ließ er sich als Arzt in Wien nieder, wo er bald eine Professur erhielt und den Anatomie-Unterricht übernahm. Im Oktober 1558 die Pest auszubrechen drohte, wurde Aicholz zum magister sanitatis vorgeschlagen. Er war seit 1559 fünfmal Dekan und 1574 Rektor. 1581 wurde er zu Kaiser Rudolf II. nach Prag gerufen. Zusammen mit Paul Fabricius legte er dort einen botanischen Garten an. Carolus Clusius, der mit ihm eng befreundet war, wohnte in seinem Wiener Haus. Siehe K. Schmadelbauer, "Aicholz, Johann Emmerich", in Neue Deutsche Biographie, vol. 1 (Berlin, 1953), 117-118.

${ }^{50}$ Es handelt sich dabei um die Edition von Gelehrtenbriefen von Thomas Crenius (16481728): Animadversionum philologicarum et historicarum pars VII (Leiden, 1700), 229-230.

51 János Vitus Balsaráti (1529-1575) studierte ab 1549 in Wittenberg und wechselte von der Theologie auf Anraten von Melanchthon zur Medizin. 1556 setzte er seine Studien in Italien fort, unterwegs besuchte er Conrad Gessner und Heinrich Bullinger in Zürich. In Padua erwarb er den medizinischen Doktorgrad und besuchte Bologna sowie Rom. 1564 nach Ungarn zurückgekehrt, wirkte er bei seinem Mäzen Gábor Perényi als Leibarzt, später als Pfarrer und als Lehrer am reformierten Kolleg zu Sárospatak, wo er medizinische und theologische Manuskripte erstellte, die jedoch unveröffentlicht blieben und als verschollen gelten: Á. Ritoók-Szalay, "János Balsaráti Vitus, ein ungarischer Doktor der Medizin im 16. Jahrhundert", in A. Szabó (ed.), Iter Germanicum. Deutsch- 
mythologischen und biblischen Querverweisen gespickte Humanisten ähnliche Fachsimpelei über die Benennung und Genießbarkeit der Alraune (Mandragora). Flüchtige Erwähnung finden neben biblischen Namen (Jonas, Rahel, Lea) auch zeitgenössische Größen wie: Luther, Aicholz, (Melchior) Guilandinus, (Jean) Mercerus und Quinquarboreus. Die beiden Letztgenannten sollen Sprachlehrer von Clusius in Paris gewesen sein. Der Brief endet mit dem hilfsbereiten Angebot weiteres botanisches "Tauschgut" zu senden und überflüssiges Material zu übernehmen, eine typische Haltung für zwei leidenschaftliche Botaniker.

Nur knapp sechs Wochen nach dem zweiten Brief verfasste der Brünner Arzt sein drittes Schreiben, am 14. Mai 1575, ein weiteres zeittypisches Zeugnis des lebhaften Austausches zweier botanisierender Ärzte des 16. Jahrhunderts. Bereits die Ansprache reflektiert mehr Nähe und ein gefestigteres Verhältnis zwischen den beiden Korrespondenzpartnern als im ersten Brief. Gleich zu Beginn bringt Jordanus seinen Unmut über einen namentlich nicht benannten Gewürzhändler zum Ausdruck, vermutlich wegen eines nicht näher erläuterten Versäumnisses oder einer ärgerlichen Fehlleistung. Seinen örtlichen Apotheker dagegen empfiehlt er Clusius als künftigen Vermittler bei Sendung botanischen Materials, dessen Verlässlichkeit er mit einem alttestamentarischen Vergleich untermauert. ${ }^{52}$

Der zweite inhaltliche Teil des Briefes ist von seiner tiefen Besorgnis um das Schicksal des gemeinsamen Freundes Hubert Languetus (15181581) geprägt..$^{53}$ Diese Information habe er von Johannes Crato von Krafftheim, dem namhaften Humanisten und einflussreichen kaiserlichen Leibarzt erhalten. ${ }^{54}$ Der französische Diplomat, Jurist und refor-

land und die Reformierte Kirche in Ungarn im 16.-17. Jahrhundert (Budapest, 1999), 118-153; A. Szabó, Coetus Ungaricus. A wittenbergi magyar diáktársaság 1555-1613 [Coetus Ungaricus. Die ungarische Studentenschaft zu Wittenberg 1555-1613] (Budapest, 2017), 90-91. Diesen Arzt wird Jordanus noch aus seiner Studienzeit in Wittenberg gekannt haben und möglicherweise standen die beiden in Kontakt zueinander.

52 Es dürfte sich um den Brünner Apotheker Georg Ludwig handeln: Ch. Elvert (ed.), Mährische und schlesische Chroniken (Brünn, 1861).

${ }^{53}$ Siehe Anm. 19.

54 Johannes Crato von Krafftheim (1519-1585) war Sohn einer bürgerlichen Familie aus Breslau und hieß Johann Krafft. Während seiner Studien in Wittenberg (1535-1540) gehörte er als Mieter im Luthers Haushalt zu dessen engsten Kreis und als desen gab er später Luthers Tischreden heraus. Auf Einfluss von Melanchthon wandte er sich ab 1540 dem Medizinstudium und ging nach Leipzig und bald nach Padua wo er auch promovierte. Nach Verona wirkte er in Augsburg als Stadtarzt bis 1560, als er zum Leibarzt des Kaisers Ferdinand I. nach Wien berufen wurde. Er wirkte auch als Leibarzt und Rat im Hofe von 
mierte Theologe Languetus lebte von 1573 bis 1576 am Hof des Kaisers Maximilian II., den er auf seinen zahlreichen Reisen begleitete. Mit dem Tod Maximilians im Jahre 1576 war seine Verbindung mit dem Wiener Hof rasch gelöst. Das feindliche Verhalten, das ihm als einem Freund Melanchthons und als Calvinisten entgegengebracht wurde, veranlasste ihn schließlich, seine Entlassung vom Hof einzureichen. Diese Zeilen lassen darauf schließen, dass Jordanus und Languetus in enger Freundschaftsverbindung standen. Die Besorgnis um das Schicksal von Protestanten am Hof war nicht unbegründet, denn auch Clusius selbst wurde bald darauf ein "Betroffener" der konfessionellen Bereinigungsaktionen am Kaiserhof; auf Betreiben katholischer Kreise wurde 1576 auch er von Kaiser Rudolf II. seines Amtes enthoben.

Der dritte Absatz fokussiert auf die Fragestellung nach einer Wurzel, die im Handel unter dem fantasievollen Namen Serpentaria angeboten wird. Es folgt eine kurze botanische "Fachsimpelei" um die Zuordnung der Pflanze mit dem schlangenförmigen roten Wurzelwerk, und er erhofft sich Aufklärung von seinem Freund Clusius. Jordanus erwähnt auch in diesem Brief Mattioli, allerdings ohne den sonst üblichen respektvollen Ton, der einem angesehenen, älteren Kollegen gebührt. Merkwürdig erscheint im Postskript, dass Clusius seinem Freund vom Besuch seines "kaiserlichen Gartens" abgeraten haben soll, wofür Jordanus Verständnis zeigte. War vielleicht die spannungsgeladene, zunehmend protestantenfeindliche Atmosphäre am kaiserlichen Hof der Grund dafür?

Die ersten drei Briefe von Jordanus sind trotz der relativen Kürze im Vergleich zu den letzten beiden aus dem Jahr 1585 reich an Informationen und lassen weitere Korrespondenten erahnen, wodurch sein Netzwerk in der "Gelehrtenrepublik" in völlig neuem Licht erscheint. Anhand der Verweise auf Briefwechsel mit anderen herausragenden Persönlichkeiten wie Crato, Mattioli, Posthius, Languetus, Abondio, Aicholz und Freiherr von Waldstein bietet es sich an, die Suchbreite nach weiteren Jordanus-Briefen auszudehnen. Trotz der von ihm nur sehr knapp behandelten Themen konnten zahlreiche neue Erkenntnisse

Maximilian II. und dessen Sohn Rudolf II. in Wien und Prag bis 1580 als er - seinen vielen Widersachern überdrüssig - auf eigenen Wunsch vom Hofdienst befreit wurde. Zwei Jahre vor seinem Tod, 1583 kehrte er in seine Geburtsstadt Breslau zurück: V. von Fossel, "Crato von Krafftheim (1519-1585)", in Id. (ed.), Studien zur Geschichte der Medizin (Stuttgart, 1909), 24-45; G. Eis, "Johannes Crato von Crafftheim", in Neue Deutsche Biographie, vol. 3 (Berlin, 1957), 402-404; Sachs 1997 (wie Anm. 29), 232-238. 
bezüglich seines Familienlebens, seiner Interessen und seiner Bedürfnisse ebenso wie seiner menschlichen Kontakte und der Ereignisse (Kuraufenthalte, Krankheit) gewonnen werden.

Die Briefe Nr. 4 und 5 wurden von fremder Hand geschrieben, allerdings von zwei unterschiedlichen, worauf die voneinander abweichenden Handschriften schließen lässt. Beim fünften handelt es sich vermutlich nicht um das Antwortschreiben auf den vierten Brief von Jordanus an Clusius, sondern um eine Antwort auf einen nicht überlieferten Brief vom 5. Oktober 1585, der über Cornelius Frintius (Vrintz) mit Verspätung aus Wien nach Brünn übermittelt wurde.

Der Grund für das Diktieren des vierten Briefes ist einem Brief von Johannes Crato von Krafftheim vom 13. März 1585 an den gemeinsamen Freund, den Nürnberger Arzt Joachim II. Camerarius (1534-1598), $\mathrm{zu}$ entnehmen, nämlich, dass Jordanus an Schlaganfall-bedingten Lähmungen (Hemiplegie oder Hemiparese) gelitten hat und nicht mehr selbst schreiben konnte. ${ }^{55}$

Durch den dramatisch verschlechterten Gesundheitszustand des Autors bedingt, nimmt im vierten Brief die Krankheit eine zentrale Rolle ein. Der einleitenden Erläuterung für das Ausbleiben mehrerer Antwortschreiben an Clusius ist zu entnehmen, dass er seit zehn Monaten an den Folgen seiner Lähmung litt und sein kritischer Zustand für das "erzwungene Schweigen" ursächlich sei und zur Unterbrechung der Korrespondenz führte. Dafür entschuldigt er sich und bittet seinen Freund, dass dieser Umstand keineswegs ihre langjährige "unverletzte freundschaftliche Verbindung" gefährden sollte. Mit seinem Schicksal hadernd, bedauert er, dass sie sich gegenseitig in Wien und Brünn verpasst haben, und fürchtet, dass es krankheitsbedingt nicht mehr zu einem persönlichen Wiedersehen kommen würde.

Jordanus bestätigt die anerkennungsvolle Einschätzung seines Adressaten bezüglich der Person des mährischen Landeshauptmanns als richtig, den er ebenso respektvoll als "Mäzen der Gelehrten und ein äußerst kluger Erforscher der Natur" bezeichnet. Jordanus verspricht ihm, sich beim Landeshauptmann für seinen Freund Clusius einzusetzen, falls jener ihn doch besuchen würde. Es liegt die Vermutung nahe, dass

\footnotetext{
${ }^{55}$ Crato habe einen Brief von Jordanus bekommen: der unglückliche Jordanus leide an einer Lähmung (paresis), ebenso wie Laichaimer. Jordanus habe geschrieben, bzw. vielmehr seinem Sohn diktiert, dass Camerarius Verwandter (affinis) in diesem Unglück der Unglücklichste sei. Erlangen-Nürnberg, Universitätsbibliothek, Trew, Crato von Krafftheim Nr. 1226. Siehe www.aerztebriefe.de/id/00009090.
} 
der schwerkranke Jordanus sich Hoffnungen gemacht haben könnte, seinen Arztfreund Carolus Clusius als Unterstützung oder sogar als Nachfolger in seinem Amt als Protomedicus Mährens installieren zu lassen. Möglicherweise wollte er sich in dieser Angelegenheit persönlich beim Landeshauptmann Freiherr Hynko von Waldstein einsetzen. ${ }^{56}$

Im letzten Absatz seines vierten Briefes bittet er seinen Kollegen und Freund Clusius, seine wärmsten Freundschaftsbekundungen an Johann Aicholz, den Vermieter von Clusius, auszurichten.

$\mathrm{Zu}$ Beginn des für Jordanus ungewöhnlich langen fünften Briefes bestätigt er den Empfang des vorliegenden als auch eines früheren Briefes, den er wegen eines Kuraufenthaltes nicht gleich beantworten konnte. Er beantworte jetzt beide auf einmal, mit viel Mühe, nämlich einem "unerfahrenen Schreiber" diktierend, was seine Korrespondenzpartner sich richtig vorzustellen vermögen. Er bringt auch seine Absicht, den (unbekannten) Brief von Johann Aicholz beantworten zu wollen, zum Ausdruck.

Der zweite Absatz des fünften Briefes hat einen botanischmedizinischen Schwerpunkt, aus dem wir von seiner Rückkehr von einer Badefahrt erfahren. Jordanus berichtet dann ausführlich über die Anwendung einer erst im 16. Jahrhundert aus der Neuen Welt (vermutlich zunächst aus Florida) eingeführten Pflanze, Sassafras, aus dem spanischen Salsafras für Saxifraga mit französischer Vermittlung. ${ }^{57}$ Die

56 Dem Protestanten Clusius wurde von der Wiener Medizinischen Fakultät zurzeit Rudolfs II die repetitio also die Nostrifizierung seines Lizentiates von Montpellier verweigert und somit auch das Recht auf ärztliche Praxis. Siehe Schultheisz 1997 (wie Anm. 31), 189; Id. 2006 (wie Anm. 46), 139. Landeshauptmann Mährens war 1585 Freiherr Hynko von Waldstein (Hynek Brtnický z Valdštejna, 1545/48-1596), Herr auf Pirnitz (Brtnice) in Südwestmähren, ein sehr gebildeter Adliger, der an der Prager Hochschullehre bei Petrus Codicillus von Tulechow studierte. Seine Studien krönte er an der Universität Wittenberg. Er trat in den Dienst des Kaisers Ferdinand I. und führte seinen Dienst am kaiserlichen Hof unter Maximilian II. fort. Hynko von Waldstein war in kaiserlichen Diensten u.a. in Frankfurt am Main, am Papsthof und in England gewesen. Er besaß auf seinem Schloß in Pirnitz eine umfangreiche Bibliothek mit zahlreichen Schriften von Luther, Melanchthon und Chytraeus: B. Fabian, G. Kükenshöner (ed.), Handbuch der historischen Buchbestände in Deutschland, Österreich und Europa (Hildesheim, 2003), 166; M. Hemelík, "Zdeněk Brtnický z Valdštejna (Portrét renesančního šlechtice a vzdělance)" ["Porträt des Renaissance Adligen und Gelehrten Zdeněk Brtnický z Valdštejn "], Iglavia docta 6 (2014), 66. Ein Schreiben Hynko von Waldsteins an Thomas Jordanus aus 1585 befindet sich im Vorspann seines Buches De aquis medicatis Moraviae commentariolus (Frankfurt, 1586) [USTC 698299].

57 Sassafrasbaum (Sassafras albidum, Sassafras officinalis etc.), auch Fenchelholzbaum oder Nelkenzimtbaum genannt, ist eine Pflanzenart in der Familie der Lorbeergewächse (Lauraceae), die im östlichen Nordamerika weit verbreitet ist. 
zimtartig wohlriechende Baumrinde wurde seit Nicolas Monardes (1574) in Europa bekannt, später auch u.a von Dodonaeus und Clusius (Übersetzer von Monardes) für Heilzwecke bei verschiedenen Krankheiten wie Fieber, Leber-, Magen-, Milz- und Darmleiden, sogar gegen Malaria und Pest empfohlen. Der schwer leidende Jordanus schreibt an seinen Freund, dass er seit 15 Tagen diese Heilpflanze anwendete, ganz nach dessen Anweisungen, von dem er diese auch erhielt, doch war er mit der erwarteten Heilwirkung noch nicht zufrieden. Vermutlich war, im Sinne der damals herrschenden Lehrmeinung über die Funktionalität des menschlichen Organismus, nach der Viersäftelehre eine stärkere schweißtreibende Wirkung des Sassafras zu erwarten gewesen. Er schreibt an seinen Freund, dass er mit der Behandlung, trotz der Ohnmachtsanfälle, die er während der Selbstbehandlung erlitt, fortfahren will. Über die richtige Art der Anwendung dieser Pflanze war er aber verunsichert, insbesondere, weil eine diesbezügliche Abschrift von Clusius in seiner Bibliothek abhandengekommen ist, die er sogar mit einer einschlägigen Empfehlung von Crato ergänzt haben soll. ${ }^{58}$

Der Brünner Mediziner kündigte in seinem Schreiben die Zusendung von "feinem mährischen Papier" als Gegenleistung an Clusius an, der ihn offensichtlich kurz davor in Brünn besucht und seine Familie beschenkt hatte. Auf diesen Besuch verweist er im nächsten Absatz und übermittelt den Dank seiner Frau und seine Kinder. Ganz merkwürdig erscheint der skeptische Hinweis von Jordanus an das noch nicht eingelöste Versprechen der wohl älteren Tochter an die Mutter, ein Kränzchen als Dankeschön an Clusius nach Wien schicken zu wollen.

Sein Gesundheitszustand und die jüngsten Ereignisse, zum Beispiel seine recht kryptisch gehaltenen Beobachtungen während des jüngsten Badeaufenthaltes, kommen wieder auf die Tagesordnung, und er berichtet sachlich über die aus seiner Sicht "zu geringen Fortschritte" in der Genesung. Die Beweglichkeit der Glieder habe sich teils nur wenig, teils überhaupt nicht gebessert, der Appetit sei "unterdrückt", und er beschreibt sogar zwei Zwischenfälle (Zusammenbrüche bzw. Kollapse) während des jüngsten Kuraufenthaltes. Die Beschreibung der Symptome bezüglich des Ausstoßes einer großen Menge an Schleim und Eiter erlaubt keine sichere diagnostische Zuordnung und schon gar keine

${ }^{58}$ Crato starb in Breslau nur wenige Tage vor diesem Brief (19. Oktober 1585). Die Todesnachricht des geschätzten gemeinsamen Freundes und Kollegen scheint Jordanus noch nicht erhalten zu haben. 
Ferndiagnose. Magenbeschwerden und ein Katarrh sowie wiederkehrende Hautausschläge plagten den körperlich geschwächten, aber geistig noch vitalen Brünner Arzt. Einen beeindruckenden Beweis dafür liefert der Absatz, in dem er seinen Wunsch äußert, dass ihm Clusius die aktuellste Liste der jüngst in Frankfurt gedruckten Bücher von seinem Wiener Buchhändler besorgen und zuschicken oder zumindest zum Lesen ausleihen möge. Es dürfte sich um das Verlagshaus von Andreas Wechel gehandelt haben, bei welchem er selbst einige seiner Werke veröffentlichte und in dem das im Jahr 1586 erschienene Buch über die Heilbäder Mährens posthum veröffentlicht wurde. ${ }^{59}$

Im letzten Absatz entschuldigt Jordanus sich wegen der Nichtbeantwortung der Briefe von Aicholz. ${ }^{60}$ Er verspricht aber Wiedergutmachung, sobald er wieder genesen sein werde. Die Hoffnung auf Genesung, die er offensichtlich zum Zeitpunkt des Diktierens dieses Briefes noch hegte, ging nicht in Erfüllung, denn er starb dreieinhalb Monate später, am 6. Februar 1586. ${ }^{61}$

Im Abschlussteil des Briefes werden noch zwei Personen genannt. In einem auffällig knappen Satz verweist er auf Doktor Cromer, der persönlich Clusius antworten sollte. Dieser Arzt ist umso interessanter, weil es sich ja um Achilles Cromer (Cromerus) handelt, der kurz nach dem Tod von Jordanus nicht nur sein Amtsnachfolger wurde, sondern 1586 auch dessen Witwe heiratete. ${ }^{62}$

59 Thomas Jordanus, De aquis medicatis Moraviae commentariolus (Frankfurt, 1586) [USTC 698299]. Andreas Wechels Vater Christian stammte aus Basel und wirkte, wie später auch sein Sohn, als angesehener Drucker und Verleger in Paris. Als Anhänger der Reformation musste Andreas Wechel aus Paris nach Frankfurt am Main (1573) fliehen und wirkte dort erfolgreich, mit seinem Sohn Johann, bis 1600. Möglicherweise kannte Thomas Jordanus die Familie Wechel noch aus seiner Studienzeit in Paris. Siehe K. Faulmann, Illustrierte Geschichte der Buchdruckerkunst mit besonderer Berücksichtigung ihrer technischen Entwicklung bis zur Gegenwart (Wien - Leipzig, 1882), 266-267.

${ }^{60}$ Derzeit sind uns keine Briefe zwischen Aicholz und Jordanus bekannt.

61 In den "Notizen über das Leben und Chronik des (Brünner) Ratsherrn und Apothekers Georg Ludwig" wird der Todestag des Brünner Arztes wie folgt dokumentiert: "Den 6. February starb der hochgelehrte Thomas Jordan a Clausenburg und den 12 dito bei S. Johannes in der Kirche begraben." P. Ritter von Clumecky (ed.), Des Ratsherrn und Apothekers Georg Ludwig Chronik von Brünn (1555-1604) (Brünn, 1859), 19. In der Sankt Johannes-Kirche (Minoriten), die als Bestattungsort von Jordanus von den meisten Biographen angegeben wird, befindet sich weder sein Grabstein noch eine Gedenktafel. Vermutlich wurden die Grabplatten im Zuge der Gegenreformation entfernt.

62 Aus der Korrespondenz zwischen dem Arzt Achilles Cromerus und Clusius sowie dem Nürnberger Arzt, Botaniker und Universalgelehrten Joachim II. Camerarius sind weitere Angaben über Jordanus auch nach dessen Tod am 6. Februar 1586 und seine Familie zu entnehmen. 
Es folgt eine weitere Freundschaftsbekundung und ein Gruß an Antonio Abondio (Abundius). Jordanus entschuldigt sich, dass er in Brünn keinen "italienischen Schreiber" finden könne. Mutmaßlich geht es darum, dass er sonst mit dem Hofkünstler Abondio in dessen italienischer Muttersprache kommunizierte und in seinem Brünner Umfeld keinen fand, der sein Diktat auf Italienisch hätte niederschreiben können. Er lässt Abondio durch Clusius grüßen. Mit dem Italiener verband ihn eine langjährige Bekanntschaft, vermutlich noch aus der gemeinsamen Wiener Zeit. Der gefeierte Hofmedailleur und Maler Antonio Abondio fertigte 1570 eine vergoldete Silbermedaille von Thomas Jordanus an (ABBILDUNG 1-2). ${ }^{63}$

Die Freundschaftsbekundungen und Entschuldigungen wegen der krankheitsbedingten Verzögerungen oder gar des Ausbleibens von Antworten auf die Briefe von Freunden treten in den letzten beiden Briefen in den Vordergrund. Jordanus ist von großer Sorge um den möglichen Verlust von Freunden geplagt und sehr bemüht, den Briefkontakt zumindest $\mathrm{zu}$ seinen besten und treuesten Freunden, wie Clusius, aufrechtzuerhalten. Die Ergebnisse dieses Eifers sind die beiden Diktate aus dem Jahr 1585. Der Abschlussgruß "Dein in alter Verbundenheit und Vertrautheit der aufrichtigste und engste Freund" bezeugt die tiefe freundschaftliche Verbindung von Thomas Jordanus zu seinem Arztkollegen Carolus Clusius.

Der Brünner Landeschefarzt siebenbürgischer Herkunft war Teil der wiederaufblühenden, experimentierenden, botanisierenden Medizin, und

\footnotetext{
${ }^{63}$ Abundius hieß Antonio Abondio (1538-1591) und war ein italienischer Maler und Medailleur, der von 1556-1580 als Porträtist am kaiserlichen Hof zu Wien, später auch in Prag wirkte. Von ihm stammt die Medaille von Thomas Jordanus (1570) "von welcher nur in ein einziges beglaubigtes Exemplar in der Brettauerschen Wiener Sammlung existiert" (Magyary-Kossa 1935, wie Anm. 8, 274). Die genauen Entstehungsumstände der Medaille des damals 30-jährigen Arztes aus Siebenbürgen sind unbekannt. Siehe T. Gerevich, Antonio Abondio császári és királyi udvari szobrász, festö és éremkeszítö. Gróf Klebelsberg Kuno Emlékkönyv [Antonio Abondio, kaiserlicher Bildhauer, Kunstmaler und Medailleur. Gedenkbuch für Graf Kuno Klebelsberg] (Budapest, 1924), 463-497; Molnár 1939 (wie Anm. 8), 373-422; J. Ernyey, "Kolozsvári Jordán Tamás emlékérme (1570)" [“Gedenkmedaille Kolozsvári Jordán Tamás (1570)”], Numizmatikai Közlöny (1941), 8084; V. Tomáš, "Thomas Jordan vu par ses contemporaines à la médaille commémorative de 1570", Časopis lékař̃u českých 104 (1965), 1278-1279. Heutiger Standort der Medaille ist das Institut für Numismatik und Geldgeschichte, Universität Wien. Siehe E. Holzmair, Medicina in nummis: Sammlung Dr. Josef Brettauer. Unveränderter Nachdruck des Katalogs von Dr. Eduard Holzmair aus 1937 mit einem Vorwort von Robert Göbl (Wien, 1989), 117-120 (Nr. 575).
} 
somit ein würdiger Freund von Clusius. Typisch für ihre Zeit war Folgendes:

Ein außergewöhnliches Netz von Kontakten entspann sich zwischen Gelehrten in Italien, Frankreich, der Schweiz, Deutschland und den Niederlanden, die alle die Leidenschaft für die res herbaria teilten, für die Dinge, die mit Pflanzen zu tun haben. Sie hatten keine Klubs oder andere Stätten, an denen sie sich regelmäßig trafen. Es gab keine wissenschaftlichen Zeitschriften, in denen Ansichten ausgetauscht und Ideen verbreitet werden konnten, auch keine Gesellschaften, in denen sich Gleichgesinnte zusammenschlossen. Trotzdem breitete sich das Netzwerk immer weiter aus und umfasste Apotheker, Künstler, Geistliche katholischer wie protestantischer Observanz, Ärzte, Humanisten, Schulmeister und wohlhabende Müßiggänger, doch ihr gemeinsames Interesse an Pflanzen war jetzt stärker als die sozialen Vorurteile, die sie früher vielleicht getrennt hätten. ${ }^{64}$

Auch bei dem geschilderten "Selbstversuch" mit der Anwendung von Sassafras bei seiner schweren Erkrankung nutzt der Brünner Arzt die einschlägige Expertise von führenden Protagonisten der "botanisierenden Gelehrtenrepublik" wie seine Freunde Crato und Clusius. Die schwerwiegende eigene Krankheit veranlasst ihn, auf die Bewertung der Heilwirkung von neuen pflanzlichen Wirkstoffen und der Heilbädern zu achten. Er beschreibt seine Beobachtungen, Wirkungen wie Nebenwirkungen, und urteilt aus medizinischer Sicht darüber.

Als neue Erkenntnis bezüglich der Biografie von Jordanus zählt sein Interesse für Pflanzen und, dass er auch als Botaniker aktiv war, wie viele Ärzte seiner Zeit. Entsprechend besaß auch er einen eigenen botanischen Garten in Brünn, in dem er neue und interessante Pflanzen anbaute, und nahm aktiv am Austausch von Pflanzen und Drogen, aber vor allem am neuen botanischen Wissen teil. Diesbezüglich waren die namhaftesten Botaniker des Jahrhunderts, wie Clusius, Crato, Mattioli, Posthius und Aicholz, seine Austauschpartner, wie das seinen Briefen hervorgeht. Es ist anzunehmen, dass seine Beschäftigung mit Botanik tiefgründig und recht facettenreich gewesen sein dürfte obwohl er kein botanisches Werk hinterließ.

${ }^{64}$ Pavord 2008 (wie Anm. 34), 295. 


\section{Appendix}

\section{Jordanus an Clusius (Brünn, 27. Juni 1574) ${ }^{65}$}

Thomas Iordanus clarissimo Domino Carolo Clusio salutem dicit.

Accepi perlegique quem misisti mihi librum. Fateor quoque me illo in variis dubiis solvendis plurimum esse adiutum. Gratias tibi ago quam maximas; rependerem, si quid te dignum hic esse cognoscerem. Si quando huc

5 veniendi animus fuerit, gratus eris hospes et licet nihil nostris montibus insolitum esse suspicer, non negarim tamen tua indefessa diligentia pervestigari posse aliqua quae meam facile praeteriere negligentiam.

Papaver cornutum flore pumiceo hic frequens est, cuius semina Mattiolus nuper ad se mitti voluit. E tuis seminibus nihildum prodiit. Anno elapso habui

10 a Pustio unum floris solis semen; excessit septem ulnas cum dimidia plantae altitudo. Qui fit, quod tuorum auctorum neuter eius mentionem faciat?

Quem vero tu calumniatorem tuum nominas, non licet ariolari, scire tamen velim.

Audivi hic e subcamerario Ferdinandum quondam Imperatorem pientissi-

15 mum, cum iter per Moraviam faceret, reperisse quandam herbam cuius, cum omnes in comitatu ignaros esse videret, iussit effodi radicem longissimam, ut multae horae ea eruenda absumerentur, appellarique taglohn, quasi diei mercedem, quod eius solius radicis evulsio totius diei exigeret mercedem. Nota illi est quidem, sed ob illius infinitas occupationes nunquam vacavit ut 20 mihi eam monstraret. Ad piscinarum margines crebram dicit neque tamen nymphaearum dicit. Tu, si quid de ea exploratum habueris, ne pigeat indicare. Vale, mi Domine Carole, salutato Domino Aicholzio. Brunae, 27 Iunii 1574.

[Adresse:] Clarissimo viro, Domino Carolo Clusio, Augustalis horti Viennae praefecto, amico suo longe charissimo.

25 [Von Clusius' Hand:] Iordani. 1574. Bruna, 27 Iunii ad meas $\uparrow^{*} \dagger$ Iunii. Accepi Viennae, 1 $1^{\text {a }}$ Iulii. Respondi 24 eiusdem.

$\mathbf{1 2}$ ariolari scripsimus alio $m s$

${ }^{65}$ Siehe www.aerztebriefe.de/id/00002217.

${ }^{67}$ Im Clusius' Rariorum plantarum historia, lib. 5 (Antwerpen, 1601), xci, finden sich vier Pflanzen mit ähnlichen Namen: Papaver corniculatum flavo flo. mit gelben Blüten, Papaver cornutum foeniceo flo. mit roten, Papaver violaceo flo. mit lila, sowie Papaver cornutum foeniceo pallesc. flo. mit "bleicher" Blüte. Er erwähnt, dass diese Pflanzenart u.a. auch in Mähren und Böhmen vorkommt. Papaver cornutum existiert heute als Synonym für Glaucum flavum (Gelber Hornmohn). 


\section{Übersetzung}

Thomas Jordanus grüßt den sehr berühmten Herrn Carolus Clusius.

Das Buch, das du mir geschickt hast, habe ich bekommen und durchgelesen. Auch gestehe ich, dass es mich bei der Lösung verschiedener Zweifelsfälle sehr unterstützt hat. Ich sage dir größtmöglichen Dank; wenn ich wüsste, dass es hier etwas gibt, das deiner würdig ist, würde ich mich revanchieren. Solltest du irgendwann die Absicht haben, hierher zu kommen, wirst du ein willkommener Gast sein, und obwohl ich den Verdacht habe, dass an unseren Bergen nichts ungewöhnlich ist, möchte ich dennoch mit Bestimmtheit sagen, dass deine unermüdliche Sorgfalt etwas aufspüren kann, das meiner Nachlässigkeit leicht entgangen ist.

Der Hornmohn mit bimssteinfarbener Blüte kommt hier häufig vor, Samen davon wollte neulich Mattioli zugeschickt bekommen. ${ }^{66}$ Von deinen Samen ist noch nichts aufgegangen. Im abgelaufenen Jahr erhielt ich von Posthius einen Setzling der Sonnenblume; die Höhe der Pflanze überschritt sieben und eine halbe Elle. ${ }^{67}$ Wie kommt es, dass keiner von deinen beiden Autoren dies erwähnt?

Wen du aber deinen falschen Ankläger nennst, vermag ich nicht vorherzusagen, wissen möchte ich es dennoch.

Ich habe von einem Unterkämmerer gehört, dass einst der sehr fromme Kaiser Ferdinand, als er unterwegs durch Mähren war, ein bestimmtes Kraut gefunden habe, dessen sehr lange Wurzel, als er gesehen habe, dass alle in seiner Begleitung unkundig waren, er habe sie ausgraben lassen, so dass viele Stunden damit verbracht worden seien, diese herauszureißen, und diese werde "Taglohn" genannt, sozusagen "Lohn eines Tages", weil das Herausreißen dieser einzigen Wurzel den Lohn eines ganzen Tages erfordert habe. ${ }^{68} \mathrm{Ihm}$ ist die Pflanze zwar bekannt, doch wegen seiner endlosen Beschäftigungen hatte er niemals die Zeit, sie mir zu zeigen; er sagt, sie sei häufig am Rand von Fischteichen und dass sie dennoch nicht zu den Seerosen gehöre. Wenn du irgendetwas darüber in Erfahrung gebracht haben solltest, lass es dich nicht verdrießen, es mir anzuzeigen.

Lebe wohl, mein Herr Carolus, grüße Herrn Aicholz. Brünn, den 27. Juni 1574.

[Adresse:] Dem hochberühmten Mann, Herrn Carolus Clusius, Direktor des kaiserlichen Gartens in Wien, seinem weitaus liebsten Freund.

[Von Clusius' Hand:] Von Jordanus. Brünn, 27. Juni 1574 auf meinen Brief vom *. Juni. Von mir erhalten in Wien am 1. Juli, beantwortet am 24. desselben.

${ }^{67}$ Legt man die Böhmische Elle von rund $59 \mathrm{~cm}$ zugrunde, dürfte sich die Höhe der Pflanze auf ca. 4,5 m belaufen haben.

${ }^{68} \mathrm{Zu}$ dieser Anekdote konnte bislang nichts Näheres ermittelt werden. Die Regierung des genannten Ferdinand als Kaiser fällt in die Jahre 1556-1564. Da Ferdinand I. aber schon seit 1526 Herrscher von Böhmen und Mähren war, könnte die Episode auch sehr viel weiter zurückliegen, wofür der Ton des Briefes zu sprechen scheint.

Humanistica Lovaniensia 67.2 (2018), 343-378 


\section{Jordanus an Clusius (Brünn, 5. April 1575) ${ }^{69}$}

Thomas Iordanus Domino Carolo Clusio salutem plurimam dicit.

Pro bulbis est quod tibi agam gratias. Venetiis cum tulipanis semel afferri curaveram illustri heroinae, Domini Marsalii nostri coniugi, alias nunquam hic visas arbitror. Nucleos prunorum quos petis sole non excoctorum faciam,

5 si vixero, ut arbor integra in tuum usum asservetur, neque ante maturitatem decerpatur fructus, quibus et vesci poteris, et nucleos quo placuerit transmittere. Accipe e terra quid effossum, mumiam nostri omnium rerum imperiti dicunt. Myrham vidi in Austria effossam huic similem. Ego ex odore, suffitu, tum accensione, quod ardet, succino congenerem facio.

10 Censuram tuam cognoscere cupio. Addo bolum vel terram medicamentosam ex Hungaria, quam ut apud Dominum Aicholtzium tibi visam minime ambigo: ita miror aliam speciem et odore et gustu aromaticam, oleosam, resinae vel bituminis quid redolentem. Adulteratam dixissem, nisi is, sub cuius ditione prodit, mihi Viennae obtulisset, et Iohannes Vitus, medicus

15 Hungarus sat celebris, Beregzazii specubus et cavernis olei instar stillare, ubi autem aerem attigerit, in lapidem concrescere retulisset. Petrolei aut gagalis paene refert odorem. Et sic $\chi \rho v ́ \sigma 1 \alpha \chi \alpha \lambda \kappa \varepsilon i ́ \alpha v$.

Praeterea scio, mi Clusi, te Lutetiae sub Mercero Chaldaeae linguae operam dedisse et Hebraeae sub Quinquarboreo. Quid est in Genesi, capite

20 XXX, 14-15-16, Dudaim fructus, quo Iacobum maritum mercata est a Rachele soror Lia? Lutherus Halicacabum vertit; vulgatus codex mandragoras et Gallicus habent. Curiosum me dices? Delectatus sum Guilandini Kikaionis elucidatione ex Iona Prophaeta, et hinc magnifacio usum eius linguae in explanandis stirpibus.

25 Esui gratam mandragoram dicere non ausim, qui nunquam gustarim, licet poma saepe viderim. Num campis Palaestinis obvia passim, vel ob raritatem erant expetita? Quod prius videtur annuere Moses, vel tantum sui advexerunt desiderium, ut noctem largiretur, mercata esum Rachel. In vesicaria, solano, licet fructus esitari multos viderim, quid inest voluptatis? Si haec

30 perpenderis per otiumque ad me scripseris, gratum sum habiturus.

Per hunc autem tabellarium, si quid superest seminum, rogo mecum communices. Faciam et ipse semper quae grata tibi fore cognovero.

Vale, salutato Domino Aicholtzio. Brunnae, 5 Aprilis 1575.

19 Quinquarboreo scripsimus Zvinquantoreo ed.

\footnotetext{
${ }^{69}$ Siehe www.aerztebriefe.de/id/00035708.

${ }^{71}$ Asarum Europaeum.

${ }^{72}$ Es handelt sich um János Vitus Balsaráti. Siehe Anm. 51.

${ }^{73}$ Eine stark riechende Pflanze, die in den Feldern Palästinas gefunden wurde. Möglicherweise ist es die mythologische Zauberpflanze die Gemeine Alraume, Mandragora officinarum, auch Liebesapfel genannt, ein Verwandter des Apfels von Sodom.

${ }^{74}$ Eruca vesicaria. ${ }^{75}$ Solanaceae.
} 


\section{Übersetzung}

Thomas Jordanus grüßt herzlich Herrn Carolus Clusius.

Besonderer Dank gebührt Dir für die Zwiebeln. Ich habe einmal einige Zwiebeln, zusammen mit Tulpen aus Venedig, für die gnädige Gattin unseres Herrn Marsilius bringen lassen, aber ich glaube nicht, dass ich jemals so etwas hier gesehen habe. Was die von Dir angeforderten, nicht von der Sonne getrockneten Pflaumenkerne anbelangt, wenn ich noch am Leben bin, so werde ich dafür Sorge tragen, dass ein ganzer Baum für Deine Verwendung aufgehoben wird bzw. nur reife Früchte gepflückt werden, die Du nach Belieben essen, oder deren Samen Du versenden kannst, wohin Du eben willst. Ich schicke dir etwas, das aus der Erde ausgegraben wurde und unsere völlig ignoranten Landsläute Mumie nennen. In Österreich habe ich einmal eine Art Myrrha (Harz) gesehen. Aufgrund des Geruchs, Rauches und der Ausdünstung des gebrannten Materials halte ich es mit der gemeinen Haselwurz verwandt. ${ }^{70}$

Ich möchte deine Meinung hören. Ich schicke dir ein Stück Heilerde oder Heilscholle aus Ungarn: Ich bin sicher, du hast sie bei Aicholz gesehen, aber ich denke, das ist eine besondere Sache. Der Geruch und der Geschmack waren ölig, harzig oder nach Bitumen riechend. Ich würde es für Fälschung halten, wenn mir es in Wien nicht jemand gegeben hätte, aus dessen Heimat das Material kommt und wenn mir nicht Joannes Vitus, ein berühmter ungarischer Arzt, einmal darüber erzählt hätte, dass dieses Material in den Höhlen und Hohlräumen um Beregszász wie Öl tropf, aber wenn es mit der Luft in Kontakt kommt, versteinert es sich gleich. ${ }^{71}$ Sein Duft erinnert uns an den Erdöls oder Gagalisöls. Deshalb heißt es $\chi \rho v ́ \sigma ı \alpha \chi \alpha \lambda \kappa \varepsilon i ́ \alpha v$ (Golderz).

Ich weiß auch, Clusius, dass Du bei Mercerus in Paris und bei Cinquarbres die hebräischen Sprache studiert hast. Erzähl mir, was man in 1. Mose 30.14-16 "Dudaim" nennt, womit Lea von Rachels Mann, Jacob, kaufte?72 Luther übersetzte es als "Halicacabus", in der Vulgata und bei den Franzosen heißt es Mandragora. Denkst du ich bin zu neugierig? Mir gefiel die Erklärung von Guilandinus anhand des Buches des Propheten Jonas sehr gut, deshalb befürworte ich einen linguistischen Ansatz bei der Identifizierung von Pflanzen.

Die Mandragora wage ich nicht als schmackhaft zu bezeichnen, da ich sie nie probiert habe, obwohl ich die Frucht selbst oft gesehen habe. Sollte sie auf den Feldern Palästinas häufig vorkommen, oder ist es gerade ihre Seltenheit, die der Alraune Wert verleiht? Moses scheint die Erstere zu bevorzugen, denn Rachel besorgte die Früchte nur damit Lea ihren Wunsch erfüllen und eine Nacht mit Jacob verbringen kann. Und welche Freude hat der Mensch zum Beispiel beim Genuss von Senfrauke ${ }^{73}$ oder Nachtschatten ${ }^{74}$ zumal ich oft gesehen habe, dass sie konsumiert werden? Ich wäre Dir überaus dankbar, wenn Du darüber nachdenken würdest und wenn Du dazu kämest mir Deine Meinung zu schreiben.

Wenn Du irgendwelche Samen übrig hast, schick sie mir bitte durch den Postboten zu. Ich selbst schicke Dir gerne alles, was Du magst.

Lebe wohl. Ich heiße Aicholz willkommen. Brünn, 5. April 1575. 


\section{Jordanus an Clusius (Brünn, 14. Mai 1575) ${ }^{75}$}

Thomas Iordanus Domino Clusio salutem dicit.

A decem dierum absentia heri sub noctem reversus tuam reperi epistolam. Ut fidem tuam minime in dubium vocavi, ita detestor aromatarii perfidiam. Meus hic est pharmacoporus, cui tuto quod voles credideris, et quid de 5 Dudanim in Genesi statueris significabis.

Quid de Huberto nostro audis? Temeriter me Crato ei male multos in aula Ditis ipsius velle inquit. Velim ut se subduceret vir optimus periculo, licet adeo impavidum norim, ut extrema sit tentaturus. Ad me nihil eorum scribit; si tecum communicarit, quaeso ne me celes. Forte optimum virum veterem-

10 que amicum integerrimum iuvare possemus, de cuius salute sum perquam sollicitus.

Quaeso quae radix est aromatariis sub Serpentariae nomine usurpata. Dracontium inanis Matthioli figmentum esse, iamdudum audivi. Secundum $\dagger$ Miaspetii $\uparrow$ nec iam rubra radice observavi, licet $\dagger \operatorname{ser}^{* * * \dagger} \dagger$ caulis referat. 15 Ophioglossi tertii non est, cum habeat exilem radicem. Si est secundi, exime mihi hanc dubitationem.

Vale, salutato Domino Aicholzio. Venissem Viennam visum tuum hortum, sed quia dissuades, praeteribo. Brunae, 14. Maii 1575.

[Adresse:] Clarissimo viro, Domino Carolo Clusio, Atrebati, Augustalis 20 horti Viennae praefecto et amico suo. Viennam, in aedibus Domini Acholzii.

[Von Clusius' Hand:] Iordani. 1575. Bruna, 14 Maii ad meas 5 eiusdem. Accepi Viennae, 16 Iulii. Respondi postridie.

${ }^{75}$ Siehe www.aerztebriefe.de/id/00004267.

${ }^{77}$ Eigentlich Dodanim oder Rodanim aus Genesis 10, 4, der sog. "Völkertafel", in der Noahs Nachkommen aufgezählt werden; Dodanim war Sohn des Jawan und Enkel Noahs; unklar erscheint, inwieweit das eine positive Charakterisierung von Jordanus' pharmacoporus sein soll.

${ }^{78}$ Gemeint ist Hubert Languetus. Siehe Anm. 19.

${ }^{79}$ Dis oder Dis pater ist eine andere Bezeichnung für Pluto, den Gott der Unterwelt; im christlichen Sinne konnte Dis sogar als "Antichrist" oder "Teufel" verstanden werden. Auf jeden Fall liegt eine sehr abwertende Bezeichnung für den kaiserlichen Hof vor, wohl bedingt durch die große Sorge um den in Bedrängnis geratenen Freund. 


\section{Übersetzung}

Thomas Jordanus grüßt Herrn Clusius.

Nach einer Abwesenheit von zehn Tagen bin ich gestern zurückgekehrt und fand deinen Brief. Wie ich deine Glaubwürdigkeit keineswegs in Zweifel gezogen habe, so verabscheue ich die Treulosigkeit des Gewürzhändlers. Ich habe hier meinen Apotheker, dem du anvertrauen kannst, was du willst, und über den du äußern kannst, was man in der Genesis von Dudanim behauptet. ${ }^{76}$

Was hörst du von unserem Hubertus ${ }^{77} \mathrm{Zu}$ meinem Schrecken sagte Crato, dass ihm viele am Hofe des Dis ${ }^{78}$ übel wollen. Ich möchte, dass sich der beste Mann der Gefahr entzieht, obwohl ich ihn als so unerschrocken kenne, dass er das Äußerste wagen wird. An mich schreibt er nichts davon. Wenn er sich mit dir bespricht, verheimliche es mir bitte nicht, vielleicht könnten wir den besten Mann und alten, sehr integren Freund unterstützen, über dessen Wohlergehen ich überaus besorgt bin.

Was, bitte, ist das für eine Wurzel, die bei den Gewürzhändlern unter dem Namen "Serpentaria" in Gebrauch ist? Dass "Dracontium"79 ein Erdichtetes des eitlen Mattioli ist, habe ich schon längst gehört. Zweitens Miaspetii, doch habe ich es noch nicht mit einer roten Wurzel beobachtet, obwohl der Stengel eine schlangenartige Form ${ }^{80}$ wiedergibt. Eine Art von Ophioglossum ${ }^{81}$ ist es auch nicht, da es eine dünne Wurzel hat. Wenn das Glück es zulässt, nimm mir diesen Zweifel.

Lebe wohl; grüße Herrn Aicholz. Ich wäre nach Wien gekommen, um deinen Garten zu sehen, doch weil du abrätst, werde ich davon Abstand nehmen. Brünn, den 14. Mai 1575.

[Adresse:] Dem hochberühmten Mann, Herrn Carolus Clusius aus Arras, Leiter des kaiserlichen Gartens in Wien und seinem Freund. Wien, im Hause des Herrn Aicholz.

[Von Clusius' Hand:] Von Jordanus. Brünn, 14. Mai 1575 auf meinen Brief vom 5. desselben. Von mir erhalten in Wien am 16. Juli, beantwortet am folgenden Tage.

79 Bei der hier von Jordanus abgelehnten Identifikation der Serpentaria mit Dracontium handelt es sich wohl um die Gemeine Drachenwurz (Dracunculus vulgaris) bekannte Pflanze. In Mattiolis Kräuterbuch findet sich ein Dracunculus minor oder Kleine Drachenwurtz bzw. Schlangenkraut sowie Dracunculus minoris novella, auch Natternwurz genannt. Mattioli gibt an, dass diese auf Französisch Serpentine heißen. Siehe Kreutterbuch dess hochgelehrten und weltberühmbten Herrn Petri Andreae Matthioli, jetzt widerumb mit vielen schönen neuen Figuren, zum 4. Mal gemehret und verfertiget durch Joachimum Camerarium (Frankfurt/Main, 1590) [USTC 670216], 190-191.

${ }^{80}$ Dieser Satz bietet einige Probleme: Es ist unbekannt ob es eine Pflanze mit dem italienischen Namen Miaspetti ("Erwarte mich" wie z.B. "Vergissmeinnicht") gibt. Auch die Beschreibung des Stängels (caulis) gibt Rätsel auf, da sich ein Wort durch einen verformten Buchstaben der Deutung entzieht; möglicherweise geht es um die schlangenartige Form, wozu immerhin der Pflanzenname Serpentaria (Natterwurz) passt.

${ }^{81}$ Nach heutiger botanischer Auffassung handelt es sich um Natterwurz, eine Farngattung. 


\section{Jordanus an Clusius (Brünn, 17. Juni 1585) ${ }^{82}$}

Salve.

Fatendum mihi est etiam invito, mi Clusi, me in aere tuo esse ob neglectum responsum ad epistolas quasdam tuas. Atqui non existimaram me in manus foeneratoris tam rigidi et severi incidisse, qui nullam admitteret dilationem.

5 Decimus effluxit mensis a quo misere torqueor ita, ut bona fide dicere ausim, etsi leves intercesserint indutiae, a primo invasionis morbi puncto malum semper in deteriora progressum, et quod aliis plerisque ex usu fuit, male id mihi cessit. Quo vero in statu modo sit, Cornelius testis oculatus tibi referre poterit plenius. Quantum temporis a vociferationibus, ab eiulatione, a dolorum plus

10 quam tyrannica rabie putas fuisse intervalli, quod scriptioni tribueretur? Da quaeso veniam, mi Clusi, et ne concede ut veteri et intemeratae nostrae necessitudini paucorum mensium ingratum et coactum silentium vim afferat.

Aliud maius est quod me pungit: quod te aliquot annos patria extorrem fere exulem iis non iuverim officiis, quae in tales conferri et iustitia et humanitas et

15 pietas iubent. Ea est humana conditio, ut saepe nobis multa proponamus quae ob diversos casus alienos ab instituto sortiantur affectus. Cum tu me hic, ego vero te Viennae convenire studemus, tempus effluxit ita, ut iam dubitem num in hac vita nos mutuo simus visuri. Me bona solatur conscientia quod tui nominis et amantissimus et studiosissimus fuerim semper, et si amor iste in apricum se

20 non exercuerit, per me quin id vellem non stetisse, sed de rationibus et modis dubitatum unde id testatum facere potuissem. Excusationis loco haec accipe et, si Domino visum fuerit, prorogare vitam in exiguum tempus, haec quae modo scribo firmata et probata tibi ut sint, omnem equidem dabo operam.

De promarchione recte sentis: solus est litteratorum maecenas et rerum

25 naturalium indagator solertissimus, mihi ex quo male haberi coepi non visus, neque constitit an de bulbis apud te verba fecerit. Intra paucos dies hac transiturum ad iudicia Olomuncentia existimo; tum si colloquii potestas dabitur, animum illius quid de te sentiat exploraturus sum et de eo te edocebo.

Vale; salutato Domino Aicholzio, quem prae omnibus medicis Viennensi-

30 bus semper charum et in oculis habui. Datum Brunae, 17. Iunii anno 85. Tui amantissimus Thomas Iordanus medicus.

[Adresse: keine] [Von Clusius' Hand:] Thomas Iordanus Brunae, aliena manu 17. Iunii ad meas 12. eiusdem. Accepi Viennae 21. eiusdem per Cornelium Vrintz. Respondi 4 Iulii.

12 afferat scripsimus afferant $m s \mid \mathbf{1 6}$ diversos scripsimus diversios $m s$

${ }^{82}$ Siehe http://clusiuscorrespondence.huygens.knaw.nl/edition/entry/1044 (mit Reproduktion) und www.aerztebriefe.de/id/00026443.

${ }^{84}$ Bezieht sich wohl auf die Entlassung Clusius' aus kaiserlichen Diensten im Jahre 1576.

85 Promarchio Mährens war 1585 Freiherr Hynko von Waldstein. Siehe Anm. 56. 


\section{Übersetzung}

Sei wohlbehalten.

Ich muss gestehen, auch gegen meinen Willen, mein Clusius, dass ich wegen der nicht erfolgten Antwort auf einige deiner Briefe in deiner Schuld bin, doch hätte ich nicht geglaubt, in die Hände eines so harten und strengen Wucherers gefallen zu sein, der keinen Aufschub duldete. Es sind zehn Monate verflossen, seitdem ich elend gequält werde, so dass ich guten Glaubens sagen möchte, auch wenn zwischenzeitlich ein leichter Stillstand eingetreten ist, dass seit dem ersten Augenblick des Eindringens der Krankheit das Übel immer zum Schlechteren fortgeschritten ist, und was den meisten anderen von Nutzen gewesen ist, das ist mir schlecht bekommen. Wie aber der Zustand gerade ist, wird dir Cornelius als Augenzeuge vollständiger berichten können. Wieviel zeitlichen Abstand zwischen Jammern, Wehklagen und dem mehr als tyrannischen Wüten der Schmerzen, glaubst du, hat es gegeben, den man dem Schreiben hätte gewähren können? Verzeih bitte, mein Clusius, und lass nicht $\mathrm{zu}$, dass das unwillkommene und erzwungene Schweigen weniger Monate unserer alten und unverletzten freundschaftlichen Verbindung Gewalt antut.

Anderes ist wichtiger, was mich kränkt: Dass ich dir, der du einige Jahre lang heimatlos, fast verbannt bist, ${ }^{83}$ nicht mit den Dienstleistungen geholfen habe, die man, da es Gerechtigkeit, Menschlichkeit und Gottesfürchtigkeit befehlen, solchen Menschen wie dir auftragen muss. Das ist eben das menschliche Los, dass wir uns oft vieles vornehmen, was aufgrund verschiedener zufälliger Ereignisse eine Vollendung nimmt, die abweicht von unseren ursprünglichen Vorhaben. Während du mich hier, ich aber dich in Wien zu treffen mich bemüht habe, ist die Zeit verflossen, so dass ich zweifle, ob wir einander in diesem Leben noch sehen werden. Mich tröstet mein gutes Gewissen, weil ich dich als Person immer sehr geliebt habe und dir sehr zugetan war, und wenn diese Zuneigung nicht sichtbar ausgeübt wurde, lag das nicht daran, dass ich es nicht wollte, sondern dass ich zweifelte an den Mitteln und Wegen, wodurch ich es hätte bezeugen können. Nimm dies als Entschuldigung an, und wenn es des Herrn Wille ist, mein Leben noch für geringe Zeit zu verlängern, werde ich mir entschieden jede Mühe geben, dir das, was ich gerade schreibe, zu bestätigen und glaubhaft zu machen.

Den Landeshauptmann ${ }^{84}$ betreffend, hast du das richtige Empfinden: Er allein ist ein Mäzen der Gelehrten und ein äußerst kluger Erforscher der Natur. Ich habe ihn, seitdem es mir nicht gut geht, nicht gesehen, und ich weiß nicht, ob er bei dir über die Blumenbulben gesprochen hat. In wenigen Tagen wird er, so glaube ich, wegen Gerichtsverfahren in Olmütz, hier durchkommen. Dann will ich, wenn sich die Möglichkeit eines Gespräches ergibt, seine Einstellung, was er über dich denkt, erkunden und werde dich darüber unterrichten.

Lebe wohl, grüße Herrn Aicholz, den ich mehr als alle Wiener Ärzte immer wertgeschätzt und gemocht habe. Gegeben zu Brünn, am 17. Juni im Jahre 1585. Dein dir sehr zugeneigter Thomas Jordanus, Arzt.

[Von Clusius' Hand:] 1585. Thomas Jordanus, Brünn, von fremder Hand am 17. Juni, auf meinen Brief vom 12. desselben Monats; erhalten in Wien am 21. desselben Monats durch Cornelius Vrintz, geantwortet habe ich am 4. Juli. 


\section{Jordanus an Clusius (Brünn, 27. Oktober 1585) ${ }^{85}$}

Salve.

Quas quinta die mensis ad me dedisti, vigesima quarta Frintius exhibuit, ignarus ubinam tamdiu latuerint; priores inter lavandum accepi. Utrique eadem opera respondeo, etiam Domino Doctori Aicholzio responsurus.

5 Verum quod molestum et operosum sit ad calamum dictare amanuensi imperito, neutri vestrum (et quidem genio propitio) adhuc perspectum et exploratum est.

Pro sassafrate tibi gratias ago; cum e balneis rediissem, coepi uti, et hodiernus est dies decimus quintus. De vero usu aliquid dubitamus.

10 Semuntiam sex libris aquae, id est duabus mensuris nostratibus, macero (ita videbaris monuisse quadam tua epistola), sed ignavior apparet, cum nulla prorsus excretio sequatur. Ad sudorem natura sum ineptus: duas horas eum invitavi, sed cum iam se parum exerceret secuta est lipothymia. Ita nunquam postea sudori indulsi. Pergam tamen uti.

15 Quod si interea de quibusdam monendus fuero, ne me celaveris, obsecro, destitutum exemplari quo me donaveras et aliqua annotaveras (veluti Cratonianum iudicium de sassafrate ipse ascripseram), quod furto mihi sublatum. Siquidem in bibliotheca non extat, vehementer doleo. Ut qualemcunque gratitudinem ostenderem, mitto tibi volumen chartae 20 nitidioris Moravicae, cum vix aliquid te dignum hinc mitti possit.

Coniunx et liberi pro tuis muneribus gratias summas agunt; mandavitque filiae mater ut strophiolo se et fratres redimeret, sed vereor ne promissa cadant in debitum: nosti enim verba puellarum foliis leviora caducis; quod ipsa praesente, sed invita, adiiciendum putavi.

25 Observavi nonnulla inter lavandum quae absque flagitio praeteriri non possunt; in meis thermis quae num prodierint, nondum mihi constat.

Pete indicem librorum recens Franckofurti excussorum a bibliopola vestro et fac nobis legendi copiam; perlectum si volet, recipiet.

De iis epistolam testem veteris et confirmatissimae inter nos amicitiae

30 tibi dicarem, si tua bona venia licuerit et valetudo firmior concesserit. Quae certe parum promovetur: humeri sunt agitatiores et cubitus, pedes antiquum obtinent; prostratus (ne dicam sublatus) omnis cibi appetitus. A tuo discessu bis concidi toto balnearum tempore; a primo protinus insessu materiae in

\footnotetext{
85 Siehe http://clusiuscorrespondence.huygens.knaw.nl/edition/entry/1045 (mit Reproduktion) und www.aerztebriefe.de/id/00026444.
} 


\section{Übersetzung}

Sei wohlbehalten.

Den Brief, den du am 5. Tag des Monats an mich geschickt hast, hat Frintius am 24. ausgehändigt, ohne zu wissen, wo er denn so lange verborgen war. Den früheren Brief habe ich während der Badekur empfangen. Ich beantworte beide mit derselben Mühe, auch will ich Herrn Doctor Aicholz antworten, doch darin, wie beschwerlich und mühevoll es ist, einen unerfahrenen Schreiber den Stift führen zu lassen, hat keiner von euch (und gewiss dank eines gnädigen Geistes) genaue Kenntnis und Erfahrung.

Für den Sassafras danke ich dir. Als ich von den Bädern zurückgekehrt war, begann ich ihn zu gebrauchen, und heute ist es bereits der 15. Tag. Über den rechten Gebrauch sind wir etwas im Zweifel. Ich weiche eine halbe Unze in sechs römischen Pfund Wasser ein, d.h. in zwei nach unseren heimischen Maßen (dazu rietest du mir offenbar in einem deiner Briefe), doch die Wirkung erscheint zu schwach, da gar keine Ausscheidung erfolgt. Zum Schwitzen bin ich von Natur untauglich, zwei Stunden lang habe ich den Schweißausbruch provoziert, doch wenn dieser eintrat, folgte die Ohnmacht. So habe ich mich später nie mehr dem Schwitzen hingegeben. Dennoch will ich in Zukunft fortfahren, es zu nutzen.

Wenn ich indes an bestimmte Dinge noch erinnert werden muss, beschwöre ich dich, mir dies nicht zu verschweigen, fehlt mir doch die Abschrift, die du mir geschenkt und worin du irgendwelche Anmerkungen gemacht hattest (wie ich selbst z.B. einen Hinweis Cratos zum Sassafras dazugeschrieben hatte). Diese ist mir durch einen Diebstahl genommen worden; da sie in der Bibliothek nicht vorhanden ist, bin ich außerordentlich betrübt. Um meine Dankbarkeit, in welcher Form auch immer, zu zeigen, schicke ich dir ein Bündel feinen mährischen Papiers, da kaum etwas anderes deiner würdig von hier geschickt werden kann.

Meine Gattin und die Kinder danken dir für deine Geschenke in höchstem Maße, und die Mutter hat die Tochter beauftragt, dass sie und die Brüder mit einem Kränzchen eine Gegenleistung erbringen, doch ich fürchte, dass die Versprechungen nicht eingelöst werden. Du weißt nämlich, dass die Worte von Mädchen weniger Gewicht haben als fallende Blätter, was ich, während sie selbst anwesend war, doch gegen ihren Willen glaubte anfügen zu müssen.

Beim Baden habe ich einige Dinge beobachtet, welche man nicht übergehen kann, ohne Schande auf sich zu ziehen. Ob dies auch in meinem Bad vorgekommen ist, weiß ich noch nicht sicher.

Erbitte von eurem Buchhändler ein Verzeichnis der jüngst in Frankfurt gedruckten Bücher und gib uns die Möglichkeit, es zu lesen; wenn er will, wird er es nach dem Durchlesen zurückbekommen.

Über diese Dinge würde ich dir gern einen Brief als Zeugen unserer alten und sehr gefestigten Freundschaft zueignen, wenn du es gütiger Weise erlaubst und meine bessere Gesundheit es gestattet, die gewiss zu geringe Fortschritte macht: Die Schultern sind beweglicher, bei Ellenbogen und Füßen ist alles beim Alten, jeder Drang zu essen ist stark unterdrückt, um nicht zu sagen beseitigt. Seit deinem Weggang bin ich zweimal zusammengebrochen, in der ganzen Zeit 
capite liquatae per pectus et nares tantam vim pituite effuderunt, ut tertium

35 strangulationis periculum adesset, siquidem materiae iam coctae rursum recrudescerent et tanto impetu me oppugnarent, ut nec proferre ausim, nec tibi creditu facile quot mensurae puris continuas quinque hebdomades effluxerint; et adhuc lis mihi praecipua cum catarrho et ventriculo est, quae universum corpus infestabat. Cutis scabies lavando sublata denuo repullu-

40 lat, verum non multum negotii facessit. Haec verbosius ne tibi legenti molestiam pariant vereor.

Domino Aicholzio persuadeas me sincerum et candidum (ut semper fui) eius esse amicum, et ne negligentia litterarum meam aestimet amicitiam. Ubi convaluero, neglecta compensabuntur.

45 Doctor Cromerus pro se ipse respondebit, quia aetatem habet. Abundium meo nomine salutabis et cum caream amanuensi Italo, quo minus litteris meis iam dudum ipsum inviserim, excusabis te; nostra tamen veteri benevolentia nihil decessise affirmabis.

Vale. Datum Brunae, vigesimo septimo Octobris anno 85. Tuus veteri

50 necessitudine atque familiaritate integerrimus et coniunctissimus amicus, Thomas Iordanus, medicus.

[Adresse:] Clarissimo viro, Domino Carolo Clusio, Atrebati, plantarum medicae materiae illustrissimo, nobilissimo Domino et 〈amico〉 veteri et plurimum observando.

55 [Von Clusius' Hand:] 1585. Domini Iordani. Brunae, 27 Octobris ad meas 13 Septembris et 5 Octobris. Accepi Viennae, 31 Octobris, cum volumine chartae Iglaviae. Respondi 3 Novembris.

39 investabat scripsimus infestabat $m s \mid \mathbf{4 0}$ ne scripsimus me $m s \mid \mathbf{4 9}$ tuus scripsimus tuis $m s$ 
der Bäder, sogleich vom ersten Sitzbad an, haben die flüssigen Stoffe ${ }^{86}$ im Kopf durch Brust und Nase eine solche Menge an Schleim ausgestoßen, dass als Drittes die Gefahr der Erstickung bestand. Es brach nämlich die bereits verdaute Nahrung wieder aus und griff mich mit solcher Heftigkeit an, dass ich es weder vortragen möchte noch es für dich leicht zu glauben ist, wie große Mengen an Eiter $^{87}$ fünf Wochen lang ununterbrochen ausgeflossen sind. Auch jetzt noch kämpfe ich besonders mit dem Katarrh und dem Magen, wodurch der ganze Körper angegriffen wird. Der Hautausschlag, der durch das Baden beseitigt war, bricht aufs Neue aus, bereitet aber nicht viel Unannehmlichkeit. All das, fürchte ich, bereitet dir Mühe beim Lesen, ist es doch allzu weitschweifig erzählt.

Überzeuge Herrn Aicholz davon, dass ich sein aufrichtiger und treuer Freund bin, wie ich es immer gewesen bin, und dass er meine Freundschaft nicht an der Nichtbeantwortung der Briefe bewertet; sobald ich genesen bin, werde ich das Versäumte wiedergutmachen.

Doktor Cromer ${ }^{88}$ wird für sich selbst antworten, weil er das Alter dazu hat. Grüße Abundius in meinem Namen und entschuldige dich für mich, dass ich mich nicht schon längst durch meinen Brief nach ihm erkundigt habe, habe ich doch keinen italienischen Schreiber. Versichere ihm dennoch, dass nichts von unserem alten Wohlwollen verschwunden ist.

Gegeben zu Brünn, am 27. Oktober im Jahre 1585. Dein in alter Verbundenheit und Vertrautheit aufrichtigster und engster Freund Thomas Jordanus, Arzt.

[Adresse:] Dem hochberühmten Mann, Herrn Carolus Clusius aus Arras, dem hervorragenden Kenner der Pflanzen und Medizin, dem vortrefflichen Herrn und alten und hoch zu verehrenden Freund.

[Von Clusius' Hand:] 1585. Von Herrn Jordanus. Brünn, 27. Oktober auf meine Briefe vom 13. September und 5. Oktober. Von mir erhalten in Wien am 31. Oktober mit einem Bündel Papier aus Iglau, beantwortet am 3. November.

Universitätsklinikum Regensburg robert.offner@ukr.de

Aloisiuskolleg Bonn peter.pauly@aloisiuskolleg.de

${ }^{86}$ Vermutlich geht es dabei um die sog. materia peccans, den krankheitsverursachenden, naturwidrigen Stoff aus der Viersäftelehre (Humoralpathologie).

${ }^{87}$ Möglicherweise ist erneut materia peccans gemeint.

${ }^{88}$ Gemeint ist Achilles Cromer(us) aus Neisse in Schlesien. Siehe Anm. 29. 

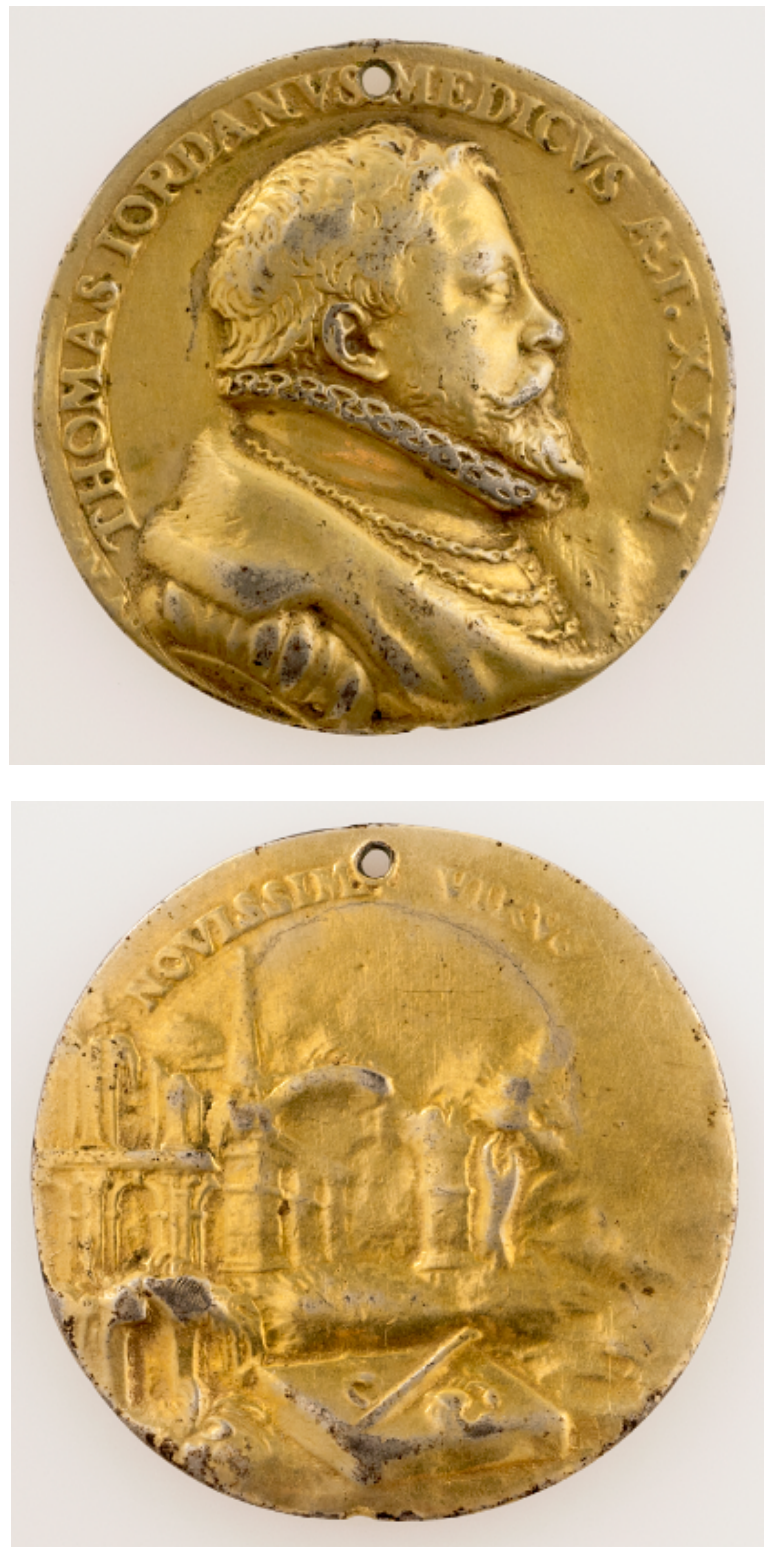

ABBILDUNG 1-2: Antonio Abondio, Medaille von

Thomas Jordanus von Klausenburg (1570). Foto: Kristina Klein, Wien. 